\title{
Imaging Spectroscopy for Soil Mapping and Monitoring
}

\author{
S. Chabrillat ${ }^{1}$ (D) E. Ben-Dor ${ }^{2} \cdot$ J. Cierniewski ${ }^{3}$ (D) . C. Gomez ${ }^{4} \cdot$ T. Schmid $^{5}$. \\ B. van Wesemael ${ }^{6}$
}

Received: 16 February 2018 / Accepted: 28 February 2019 / Published online: 20 March 2019 (c) Springer Nature B.V. 2019

\begin{abstract}
There is a renewed awareness of the finite nature of the world's soil resources, growing concern about soil security and significant uncertainties about the carrying capacity of the planet. Regular assessments of soil conditions from local through to global scales are requested, and there is a clear demand for accurate, up-to-date and spatially referenced soil information by the modelling scientific community, farmers and land users, and policy- and decision-makers. Soil and imaging spectroscopy, based on visible-near-infrared and shortwave infrared (400-2500 $\mathrm{nm}$ ) spectral reflectance, has been shown to be a proven method for the quantitative prediction of key soil surface properties. With the upcoming launch of the next generation of hyperspectral satellite sensors in the next years, a high potential to meet the demand for global soil mapping and monitoring is appearing. In this paper, we briefly review the basic concepts of soil spectroscopy with a special attention to the effects of soil roughness on reflectance and then provide a review of state of the art, achievements and perspectives in soil mapping and monitoring based on imaging spectroscopy from airand spaceborne sensors. Selected application cases are presented for the modelling of soil organic carbon, mineralogical composition, topsoil water content and characterization of soil crust, soil erosion and soil degradation stages based on airborne and simulated spaceborne imaging spectroscopy data. Further, current challenges, gaps and new directions toward enhanced soil properties modelling are presented. Overall, this paper highlights the potential and limitations of multiscale imaging spectroscopy nowadays for soil mapping and monitoring, and capabilities and requirements of upcoming spaceborne sensors as support for a more informed and sustainable use of our world's soil resources.
\end{abstract}

Keywords Soil mapping and monitoring $\cdot$ Imaging spectroscopy $\cdot$ Hyperspectral $\cdot$ Soil organic carbon · Soil mineralogical composition $\cdot$ Surface roughness $\cdot$ Soil moisture $\cdot$ Vegetation cover $\cdot$ Spaceborne instruments

S. Chabrillat

sabine.chabrillat@gfz-potsdam.de

Extended author information available on the last page of the article 


\section{Introduction}

"All natural resources... are soil or derivatives of soil. Farms, ranges, crops, and livestock, forests, irrigation water and even water power resolve themselves into questions of soil. Soil is therefore the basic natural resource" said Aldo Leopold in 1921 "Erosion and Prosperity" (Meine and Knight 1999). Nearly all of the food, fuel and fibres used by humans are produced on soil. Soil is also essential for water and ecosystem health. It is second only to the oceans as a global carbon sink, with an important role in the potential slowing of climate change. Several soil functions depend on a multitude of soil organisms, which makes soil an important part of our biodiversity. Nowadays, in the face of rapidly growing population, there is a renewed awareness of the finite nature of the world's soil resources (Hartemink and McBratney 2008), growing concern about soil security (FAO and ITPS 2015) and significant uncertainties about the carrying capacity of the planet (i.e. the number of people that the Earth can support (UNEP 2012)). Hartemink (2008) further acknowledged "Soils are back on the global agenda". This growing concern has been answered with a growing number of soil policies and regulations around the world concerned with, e.g., increasing soil degradation and loss of organic carbon in topsoils and aiming at more soil management and soil protection such as the EU Soil Thematic Strategy and Soil Framework Directive. The European Commission recognized that soil resources in many parts of Europe are being over-exploited, degraded and irreversibly lost due to inappropriate land management practices, industrial activities and land-use changes that lead to soil sealing, contamination, erosion and loss of organic carbon (JRC 2012). Soil scientists are being challenged to provide assessments of soil conditions from local to global scales (Grunwald et al. 2011; Arrouays et al. 2017). However, only a few countries have the necessary survey and monitoring programs to meet these new needs and existing global data sets are out of date. For example, the state-of-the-art Harmonized World Soil Database (FAO 2012) providing up-to-date information on world soil resources at approximately $1 \mathrm{~km}$ scale (30 arc-second database) was last updated in 2013 and recognizes that the reliability of the information contained in the database is variable. A particular issue is the clear demand for a new regional to global coverage with accurate, up-to-date and spatially referenced soil information as expressed by the scientific community, farmers and land users, and policyand decision-makers (EC 2006).

In this regard, optical remote sensing observations and in particular reflectance spectroscopy at the remote sensing scale, referred to as imaging spectroscopy (IS), or hyperspectral imaging, have been shown to be powerful techniques for the quantitative determination and modelling of a range of soil properties. These soil properties include topsoil mineralogical composition such as soil organic carbon (SOC) content, textural composition, iron or carbonate content, etc., and physical attributes (e.g., Ben-Dor et al. 2009). The attractiveness of imaging spectroscopy is that measurements are rapid and estimates of soil properties are inexpensive compared to conventional soil analyses, as it exploits the information carried out by the visible and near-infrared (Vis-NIR: 400-1100 nm) and shortwave infrared (SWIR: 1100-2500 nm) part of the electromagnetic spectrum (Goetz et al. 1985). IS has been used since more than 20 years in various soil applications such as evaluation and monitoring of soil quality and soil function (e.g., soil moisture and carbon storage), soil fertility and soil threats (e.g., acidification and erosion) and soil pedogenesis (i.e. soil formation and evolution). Further, soil degradation (salinity, erosion and deposition), soil mapping and classification, soil genesis and formation, soil contamination and soil hazards (swelling soils) are also important 
soil science issues nowadays examined with IS, enlarging the soil spectroscopy into the spatial domain from mainly airborne platforms (e.g., see review of Ben-Dor et al. 2018). Research on quantitative soil spectroscopy for the prediction of soil properties has largely benefited from technological and methodological developments over the past decades. The availability of new high signal-to-noise ratio airborne hyperspectral sensors allowed the delivery, at remote sensing scale, of laboratory-like reflectance data. Simultaneously, developments in multivariate statistics and chemometrics opened significant new possibilities toward soil spectral modelling and quantitative analyses of the physical and biochemical composition of the Earth's soil based on spectral reflectance.

In the upcoming future, a large availability of high signal-to-noise ratio satellite imaging spectrometers is expected. Several target missions having high spatial resolution and limited coverage per day are soon to be launched such as the Italian PRISMA (PRecursore IperSpettrale della Missione Applicativa) (Loizzo et al. 2018), launch 2019, $30 \mathrm{~m}$; the German EnMAP (Environmental Mapping and Analysis Program) (Guanter et al. 2015), launch 2020, $30 \mathrm{~m}$; the Japanese HISUI (Hyperspectral Imager Suite) (Matsunaga et al. 2018), to be put on the International Space Station in 2019, $30 \mathrm{~m}$; and the Italy-Israeli SHALOM (Spaceborne Hyperspectral Applicative Land and Ocean Mission) (Ben-Dor et al. 2014), launch 2024, possibly $10 \mathrm{~m}$. Among these missions, the open data policy of the German EnMAP mission is worth noting. Furthermore, several global mapping missions are planned or under study for the upcoming future such as the NASA-SBG (Surface Biology and Geology), former HyspIRI mission (Lee et al. 2015; Green 2018), HySpex2 proposed as Earth Explorer Mission ESA (Briottet et al. 2017) and the Sentinel-10/CHIME satellite proposed as ESA candidate mission (Copernicus Hyperspectral Imaging Mission for the Environment) (Rast et al. 2019). These satellites with their variable spatial coverage and different ground sampling distances will represent for soil scientists a major step toward global soil mapping and monitoring as a response to the need for accurate, up-to-date information on the world's state of soils.

Nevertheless, to be able to answer that demand and to reach the full potential of imaging spectroscopy from orbital utilization for soil mapping, challenges have been identified and, for example, linked to limitations in reference data availability (e.g., global standardized soil spectral libraries databases) and in methodological approaches and tools adequate to process the spectral data into practical soil model solutions that are globally applicable (e.g., Ben-Dor et al. 2018). An area of active research nowadays is thus on the demonstration of the potential and limitations of hyperspectral imagery for soil mapping and monitoring from airborne to spaceborne scale and on the development of enhanced databases and methods to be ready for upcoming hyperspectral satellite launches with adapted strategies and tools for the computation and delivery of global soil maps.

In this frame, we present in this paper a timely review of state of the art, challenges and limitations of imaging spectroscopy for soil applications, for young and senior research scholars, undergraduate and graduate students in Earth sciences and remote sensing, soil scientists, institutional and industrial soil entities that are concerned with the future use of remote sensing data for soil mapping and monitoring. This paper is divided into three sections. First, a review of basic concepts of soil spectroscopy for soil properties' determination is presented, including a thorough review of the effect of soil roughness on reflectance. Then, a review of the applications of imaging spectroscopy for the mapping of soil properties is presented, including selected application cases demonstrating the potential and limitations of imaging spectroscopy for the mapping of SOC, common soil properties, soil moisture, soil crust, soil erosion and degradation. Finally, a review of current challenges and gaps related to the use of air- to spaceborne imaging spectroscopy data is presented and discussed in view of future avenues of research, perspectives and user requirements for upcoming satellites. 


\section{Theory and Concepts}

\subsection{Principles of Soil Spectroscopy for Soil Properties Identification and Modelling}

The soil reflectance spectrum $(\rho)$ is a collection of values obtained at every spectral band $(\lambda)$ from the ratio of radiance $(E)$ and irradiance $(L)$ fluxes across most of the spectral region of the solar emittance function. The reflectance values are traditionally described, from a practical standpoint, by a relative ratio against a perfect reflector spectrum measured at the same geometry and position of the soils (Palmer 1982; Baumgardner et al. 1985; Jackson et al. 1987). The reflectance information is used to identify material by the nature of the reflectance spectrum it provides. The more wavelengths involved in the measurement scheme, the more information can be obtained. The nature of the spectrum is composed of absorption features of chemical constituents ("peaks") (e.g., absorption of OH of water molecules) and overall spectral shape of the physical properties ("albedo") (e.g., particle size) (Ben-Dor and Banin 1995a, b).

In soils, the optical activity of chemical chromophores (i.e. those parts of a molecule responsible for its colour) is due to vibration overtones and combination modes of functional groups at the molecular level across the SWIR spectral region and to electronic transitions in atoms across the Vis-NIR spectral regions at specific wavelengths. A compressive description on the exact soil chromophore and its electromagnetic activity can be found in, e.g., Ben-Dor et al. (1999), Stenberg et al. (2015), Demattê et al. (2015). The physical chromophores are due to scattering effects based on particle size and shape distribution in the material. The water molecule influences the absorption features at specific wavelengths that are the results of overtone and combination modes from the IR region as well as the results of the physical effects that scatter the light in a way that the spectrum shape and base line are changing. Figure 1 provides a typical soil spectrum with the direct known chromophores. It can be seen that there are physical (baseline height and spectral shape) and chemical (absorption) features. In the Vis-NIR region, electronic transitions are dominated mainly in iron oxides with also organic matter $(\mathrm{OM})$ that refer to the slope of the spectrum part (probably related to soil OM structure). In the SWIR region, the water

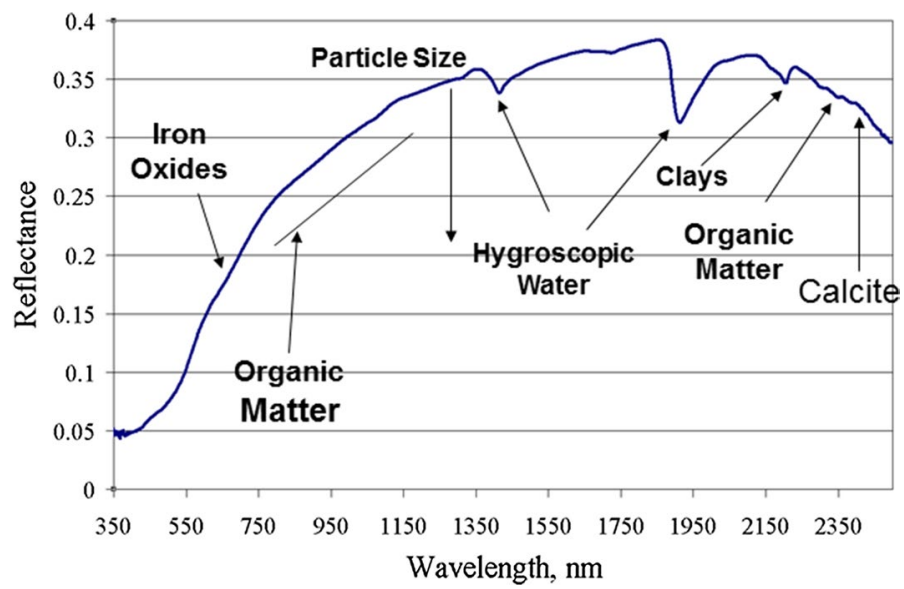

Fig. 1 A soil spectrum (Haploxeralf) that represents the major chromophores in soils (after Ben-Dor et al. 2008) 
molecules in hygroscopic water play a major role in 1.4 and $1.9 \mu \mathrm{m}$ where clay minerals and calcite are at around 2.2 and $2.3 \mu \mathrm{m}$, respectively. The wavelengths may vary based on the structure of the minerals and their crystal shape and purity. All possible absorption features and their quantum mechanisms in the Earth's crust minerals were summarized, e.g., in Ben-Dor et al. (1999).

Soil is a complex system that is extremely variable in physical structure and chemical composition both temporally and spatially. Soil spectroscopy, although being complex, can cluster several soil properties with a single measurement that can be extracted based on radiative transfer models (e.g., Hapke 1981) or empirical data-mining (chemometric) approach (Ben-Dor and Banin 1995b). The prediction of a soil spectrum from physical bases is quite difficult (Liang and Townshend 1996). Each soil property $S_{\mathrm{i}}$ has to respect the following rules to be successfully predicted by soil spectroscopy: Rule (1.1) the soil property $S_{\mathrm{i}}$ has a specific spectral signature due to a chemical or physical structure (Ben-Dor et al. 2002) or Rule (1.2) the soil property $S_{\mathrm{i}}$ is correlated with a soil property $\mathrm{S}_{\mathrm{j}}$ having a specific spectral signature due to an associated chemical or physical structure (Ben-Dor et al. 2002); and additionally Rule (2) the soil property $S_{\mathrm{i}}$ has to have a quite high amount of variability (Gomez et al. 2012a, b). Until now, and from our knowledge, the limits of the quantification of a soil property that has got a low variability within the scene have not been explored in detail as this minimum of variability may depend on (1) the studied soil property and (2) the link with other soil properties on the soil samples. This last rule implies that the predictability of a primary soil property depends on the soil diversity of the study site. For example, Ben-Dor et al. (2002) had already stressed that the soil is a complex matrix and that the spectral features of one component (e.g., OM) can be hidden or slightly shifted by another component [e.g., iron (hydr)oxides]. Nevertheless, separating the spectral information from the different soil attributes is possible as already shown in previous studies. Laboratory soil spectroscopy, linked with statistical analyses, has, for example, been used since, e.g., the earlier works of Demattê et al. (2004) over soils from São Paulo State, Brazil, for the derivation of soil survey maps and soil classes. It was the first paper applying soil spectroscopy for pedological mapping. The authors developed a spectral reflectance-based methodology that was able to evaluate soil types and soil tillage systems.

Although there is a strong relationship between the soil chromophores as observed in the spectral domain and the chemical/physical characteristics of the material, the correlation is not straightforward. This is because the spectral data are multivariate, with many reciprocal effects (Schwartz et al. 2011). Accordingly, the extraction of quantitative information on a given soil attribute using spectral information is not a simple task, especially if it is not a chromophore attribute. Malley et al. (2004) provided a summary to what soil attributes can be spectrally modelled in soils. In 2006, Rossel et al. extended the application and provided a long list of authors and soil attributes, most of which use chemometric approaches. The chemometric approach is an empirical (statically driven) method, and although no physical, chemical or other assumptions are made, the method has a strong spectroscopic basis, in which the selected bands in the model must have specific assignments. This method provides quantitative information about its chromophore that can be further used. It can be either an index, equation or a model that is extracted from the spectral information, usually combined with the reference information from traditional chemical analyses to "train" the system. Chemometrics also refers to proximate analysis of soil attributes related to the spectral analysis of soil. A sophisticated method of finding this relationship, also known as "data mining", has to be applied. As the final goal is to use the spectral model for practical remote sensing practices, it is crucial to extract the best model in a given population, rather than just finding a correlation. 
Many methods for applying data-mining approach to soil spectral information have been used and developed, from multiple linear regression (MLR) analysis (of the spectra against the chemical/physical data) through principal component analysis regression (Chang et al. 2001), partial least squares regression (PLSR) (Zhao et al. 2015), artificial neural networks (ANN) (Carmon and Ben-Dor 2017) and random forest among others. The standard procedure for developing such models will be to divide the samples into calibration and validation sets. The model is then developed on the spectral and chemical data of the calibration group and is applied on the spectral data of the validation group to predict its chemical values. The quality of the model is determined by its prediction accuracy using various statistical parameters. When a prediction model with good quality is found, it can be used to predict the chemical values of new samples with just a spectral measurement, either from point or from imaging spectrometers.

As already mentioned, spectral data are affected by various components in the soil, some of which are connected to the chemical property in question, and some not. Thus, applying preprocessing algorithms on the spectra prior to developing the model can amplify relevant spectral features and is traditionally taking place. Manipulation of spectra using derivatives and transformations to log space enables the enhancement of weak spectral features as well as minimizes physical effects (Demetriades-Shah et al. 1990). As a given dataset can be executed using several manipulation stages in a process chain, it is impossible to check many preprocessing combinations manually. Ben-Dor and Banin (1995a) suggested developing a "whole-process" possibility chain in an automated environment to enable optimal data mining, such that the best preprocessing combination could be selected. This concept is termed all possibilities approach (APA), in which all possible combinations are evaluated. Moreover, they concluded that aside from good statistical parameters and a selected processing chain, a reliable model must have solid spectral assignments for the spectral region/channels selected by the analysis. This is done by finding the important spectral ranges used by the model and examining whether the selected wavelengths have a meaningful explanation based on the physical processes described earlier.

To cope with these challenges, Schwartz et al. (2011) developed a data-mining machine termed "PARACUDA ${ }^{\circledR}$ " which runs several preprocessing spectral data manipulations. Their concept was based on a smart and single selection of calibration and validation groups from the population in question, using a cubic Latin hypercube sampling algorithm for semi-randomized grouping (Minasny and McBratney 2006). Remarkable results were obtained using the PARACUDA machine, mainly due to its automated capability to parallel-check 120 preprocessing combinations. The continued development of the system resulted in the notion that the model quality is sensitive also to the grouping stage and not only to the preprocessing combination. Moreover, the system did not have a viable spectral assignment output, which could significantly amplify the models' robustness and improve our understanding of the spectral correlations to various soil properties. As the main goal was to develop an accurate (reliable) prediction model, based on finding the best preprocessing combination and spectral assignments, a new system was recently developed to fully exploit the APA idea of the PARACUDA engine (Carmon and Ben-Dor 2017).

As the quantitative approach of spectral data mining of soils developed, many users are getting into this field and the usage is growing consistently. In this direction, the new machine learning software (such as the PARACUDA-II ${ }^{\circledR}$, Carmon and Ben-Dor 2017) or computing approach (such as random forest, Gholizadeh et al. 2015) fosters the use of soil spectroscopy for the quantitative domain. In this case, we examined how many papers have been published during the past 10 years using some keywords of soil spectroscopy (point and image) using Google. An exponential growth in both technologies was found, whereas 
the imaging is still lagging behind with respect to point spectroscopy. This is because the soil imaging spectroscopy started later than the point spectroscopy, and only recently has the image technology became more available to more users and the number of papers started to grow. The exponential pattern is not surprising and provides a promising future for the practical use of soil spectroscopy.

It should be pointed out that recently not only the optical domain (Vis-NIR-SWIR) is used for soils but also the thermal infrared part, also termed mid-infrared (mid-IR: 3-12 $\mu \mathrm{m}$ ), which shows promising capabilities. From the first paper based on Janik et al. (1998) who raised the question "Can mid-IR diffuse reflectance analysis replace soil extractions?", it is clear today that this region is important, especially for detecting silicatebearing minerals (Weksler et al. 2017). Chang et al. (2001) used a principal components regression method to determine the soil attributes from the thermal region in the laboratory. They had success with some attributes such as calcium, but not with micronutrients such as zinc or sodium. Chang and Islam (2000) constructed an ANN model based on the physical linkages among the space-time distribution of brightness temperature, soil moisture and the soil media properties. They showed that it is possible to infer soil texture from spectral reflectance properties, based on the current activities and knowledge about soil spectroscopy and analysis. Eisele et al. $(2012,2015)$ demonstrated the advantages of the 8-12 $\mu \mathrm{m}$ domain for the quantification of several soil properties such as soil texture and in particular for sand content that is hardly retrievable based on the optical domain. Similarly, Kopacková et al. (2017) were able to show that the mid-IR between 3 and $12 \mu \mathrm{m}$ is capable of providing quantitative information of selected samples of organic soil using the PARACUDA-II algorithm and demonstrated the added value of this region to the optical region. Most studies until now in IS for soils in the mid-IR were based on laboratory spectroscopy due to the lack of availability of airborne data and adapted softwares. Nevertheless, nowadays airborne thermal IS is getting more and more attention based on the release of new technology. New airborne imaging thermal spectrometers are becoming available commercially (e.g., the TASI-600 from ITRES, recently the pushbroom AisaOWL and FTIR HyperCam from Specim and Telops), and new orbital initiatives including thermal bands are now started or planned (e.g., ECOSTRESS the ECOsystem Spaceborne Thermal Radiometer Experiment on Space Station, launched in June 2018, and the planned NASASBG) (Hook et al. 2017). Thus, the thermal region of the electromagnetic spectrum aimed to be adopted for soils in addition to the optical region in future.

\subsection{Effect of Surface Roughness on Soil Reflectance}

The roughness of soils, regarded here as irregularities of their surfaces resulting from the existence of soil particles, aggregates, rock fragments and micro-relief configuration, significantly affects soil spectral reflectance. Although this impact was noticed and examined many years ago (Bowers and Hanks 1965; Brennan and Bandeen 1970; Stoner and Baumgardner 1981; Cierniewski 1987; Cierniewski and Courault 1993), it is still underappreciated (Cierniewski et al. 2015).

The spectral reflectance of soil surfaces as with many other Earth objects is anisotropic. Irregularities in soil surfaces produce shadow areas, where solar beams in field conditions or beams from an artificial light source in laboratory conditions do not directly reach the surfaces. Wave energy leaving the areas is many orders of magnitude smaller than energy reflected from directly illuminated soil fragments. Cierniewski et al. (2010) showed spectra of a ploughed soil obtained by a hyperspectral camera. The overall reflectance level of the 
shaded soil fragments was clearly lower than that related to sunlit fragments, although the shape of the two categories of these spectra was quite similar to each other.

Cultivated bare soils with dominant diffuse features usually appear brightest from the direction which gives the lowest proportion of shaded fragments. Those soil surfaces usually display a clear backscattering character with a reflectance peak toward the Sun position ('hot spot' direction) and decreasing reflectance in the direction away from the peak (Brennan and Bandeen 1970; Kriebel 1976; Milton and Webb 1987). Desert surfaces show that soil reflectance can clearly have both a backscattering and a forward-scattering character (Deering et al. 1990). The surfaces display maximum reflectance in the extreme forward-scattering direction near horizon if they are relatively smooth with a strong specular behaviour. Shoshany (1993) found that different types of desert stony pavements and rocky surfaces under varied illumination conditions exhibited an anisotropic reflection with a clear backscattering component.

Non-Lambertian behaviour is presented in Fig. 2 for two soil surfaces, one uncultivated and smooth and another cultivated and moderately rough, both with non-directional spreading of their height irregularities. Their reflectance distributions normalized to the nadir viewing in all possible directions for the chosen wavelength of $850 \mathrm{~nm}$ under clearsky conditions at various solar zenith $\left(\theta_{\mathrm{s}}\right)$ and azimuth $\left(\phi_{\mathrm{s}}\right)$ angles were predicted by a hemispherical-directional reflectance model (Cierniewski et al. 2004). The larger the soil surface irregularities and the higher the $\theta_{\mathrm{s}}$, the higher the variation of the soil directional reflectance. The variation is the most visible along the solar principal plane. Croft et al. (2012) and Wang et al. (2012) also reported this non-Lambertian behaviour of soil surfaces under laboratory conditions. How a directional furrow micro-relief can additionally complicate the reflectance of soils is shown by the results of a laboratory measuring experiment simulating the reflectance behaviour of sandy soils with furrows treated by a harrow or a seeder (Cierniewski and Guliński 2010). They found that the spectrum level (between 400 and $2300 \mathrm{~nm}$ ) for the mostly deeply furrowed surface viewed at the nadir and illuminated by sunbeams coming along the furrows was $5-10 \%$ higher than for the same surface but illuminated by sunbeams coming perpendicular to them. Under the same illumination and viewing conditions of the furrows, the level of the spectra for the surface with the deepest furrows was about $2 \%$ lower than for the three times shallower furrows.
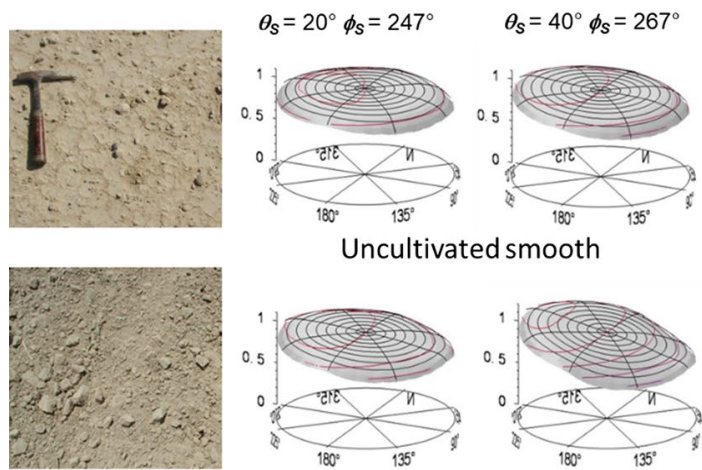

Uncultivated smooth
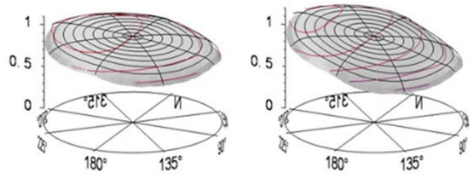

Cultivated moderately rough
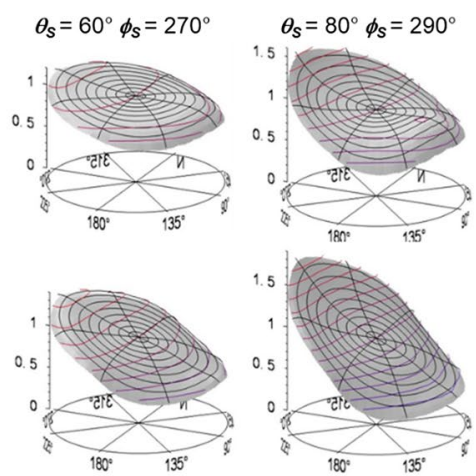

Fig. 2 Normalized directional reflectance distributions of soils for chosen wavelength of $850 \mathrm{~nm}$ under clear-sky conditions at various solar zenith $\left(\theta_{\mathrm{s}}\right)$ and azimuth $\left(\phi_{\mathrm{s}}\right)$ angles predicted by a hemispherical-directional reflectance model (after Cierniewski et al. 2004) 
Soil roughness also clearly affects albedo. Analysing broadband soil albedo variation during the day, it was found that soil roughness affected not only the overall level of that variation (Cierniewski et al. 2015), but also the intensity of the albedo, which increased from $\theta_{\mathrm{s}}$ at the local noon to about $75^{\circ}-80^{\circ}$. Rough, deeply ploughed soil surfaces showed almost no rise in albedo values for $\theta_{\mathrm{s}}$ lower than $75^{\circ}$, while the same soil, but smoothed, exhibited a gradual albedo increase at these angles. Clearly, spectral reflectance of soils covered with a crust formed by the sequential wetting and drying of their surfaces is higher than that of soils without a crust (Cipra et al. 1971; Goldshlager et al. 2010). The reflectance of disturbed soil samples increases as soil particle size decreases (Piech and Walker 1974). The smaller aggregates are more spherical in shape, but the larger ones are irregular in shape with a higher number of inter-aggregate spaces and cracks where the incident light is trapped (Coulson and Reynolds 1971). Especially after tillage treatments, the impact of soil roughness on spectral reflectance can be very variable. Matthias et al. (2000) found that, when the relatively smooth surface of a fine sandy soil was ploughed, its reflectance decreased by about $25 \%$. Potter et al. (1987) reported that, conversely, the reflectance of ploughed sandy soils increased by about $25 \%$ after rain and subsequent drying of their surface.

With the intention to as precisely as possible model processes associated with the flow of radiation between the Earth's surface and the atmosphere in longer periods of several days, a month, a season or a year, average diurnal albedo values $\left(\alpha_{\mathrm{d}}\right)$ appear to be more useful than instantaneous values. Cierniewski et al. (2013) considered the optimal time (To) to obtain spectral data of bare soils for approximating their $\alpha_{\mathrm{d}}$ values using satellite technology. They supposed that raw satellite data for the Earth's surfaces obtained in that time do not need be corrected due to the Sun position expressed by $\theta_{\mathrm{s}}$. It was anticipated that the correctness of soil $\alpha_{\mathrm{d}}$ estimation could be increased by eliminating at least one of the factors having a significant impact on the approximation of soil's $\alpha_{\mathrm{d}}$ (the effects of the atmosphere, the direction of the soil observation by satellite, which together with the direction of the Sun position determine the bidirectional reflectance of studied surfaces) and extrapolating the narrowband albedo to its broadband value, and the correctness of soil $\alpha_{\mathrm{d}}$ estimation would be higher. Struggling to minimize errors of this approximation becomes especially important in the context of the statement by Sellers et al. (1995) that global climate change models required albedo values with errors of less than $\pm 2 \%$. Cierniewski et al. (2013) analysed how strongly the roughness of soils (smooth, moderately rough and very rough) and their location in the world affect To, taking into account their latitudinal position and assuming that they were observed by a satellite in Sun-synchronous orbit at chosen dates with errors $\pm 2 \%$. It was found that morning To was expected for very rough soil earliest and for the smooth soil latest. In the afternoon, this trend was reversed. The usefulness of the orbit during the analysed dates was expressed by its length, from which observation of the soils was available with the acceptable error $\pm 2 \%$. The longest parts of the orbits, estimated as larger than $90^{\circ}$, were predicted for the morning in mid-April, while the shortest length of them, reaching only about $20^{\circ}$, was expected for the afternoon in the beginning of the astronomical summer. An attempt was also made to compare the usefulness of satellite orbits crossing the equator at local solar time 7:30 and 10:30 such as for the NOAA-15 and the MODIS (Cierniewski 2012). The earlier orbit proved to be the much more useful for observing bare soils than the later one.

A few decades ago, variation of the soil surface height was only measured along a direction using a profile meter with needles or a chain set (Gilley and Kottwitz 1995). Many years later, Moreno et al. (2008) drew attention to the fact that the use of these simple tools can be successfully replaced or supplemented by analysing the shading of soil surface 
irregularities with their directional and non-directional spreading. Now, the soil surface height is automatically recorded using laser scanners along a single or multiple straight lines (Thomsen et al. 2015). This allows for analysis of soil irregularities in the two-dimensional or three-dimensional space, respectively. Currently, the soil surface roughness is most often investigated in a three-dimensional space using methods of close range digital photogrammetry (Heng et al. 2010; Rieke-Zapp and Nearing 2005). Recently, Gilliot et al. (2017) have presented the use of photographs of a studied soil surface taken from over a dozen directions by a hand-held digital camera that moved around the area of interest. These photographs, taken together with horizontal slats, allow for the creation of digital elevation models (DEMs) of the studied surfaces, which are the basis for calculating the roughness indices of soil surfaces.

The standard deviation computed of the surface height data collected along a direction or within DEM units is the most common index for describing the soil surface roughness (Ulaby et al. 1982; Marzahn et al. 2012). Boiffin (1986) proposed the use of the description of the turtle's index, which represents the ratio between the actual length of the soil surface profile and the projected horizontal length of this profile. Later, Taconet and Ciarletti (2007) modified the reference of the index to the two-dimensional space, defining it (T3D) as the ratio of the real surface area within its basic DEM unit to its flat horizontal area. Other indices used mainly to quantify the temporal evolution of the soil surface roughness due to rainfall events are based on a semivariogram analysis (Croft et al. 2013; Rosa et al. 2012; Vermang et al. 2013).

\section{Applications of Imaging Spectroscopy for Soil Mapping}

\subsection{Common Soil Properties Mapping}

\subsubsection{Examples of Soil Properties that have been Predicted with Airborne Spectroscopy}

The mapping of soil surface properties from imaging spectroscopy in the Vis-NIR-SWIR region has emerged in the early 2000s. Since then, it has been further demonstrated and extended in many environments and for many soil properties based on different sensors and different methods. Nowadays, this technique is commonly used over bare soils on cultivated areas where: (1) soil is regularly ploughed inducing topsoil homogenization (usually 20-30 cm), (2) large proportion of bare soil and no soil crust formation are exposed, which may be ensured with a flight window during seeding of summer crops (such as maize, sugar beet or potato) or winter crops (such as winter cereals), (3) top-surface water content is low.

One of the first examples of soil property mapping was obtained using the DAIS 7915 airborne sensor in Israel (Ben-Dor et al. 2002). These authors used a two-step approach. First, they acquired field spectra using an ASD spectrometer and analysed the samples from the corresponding surfaces by means of conventional wet chemistry techniques for soil properties such as OM, soil moisture content in field conditions, saturated soil moisture content, salinity and $\mathrm{pH}$. They constructed a spectral model using MLR of the 38 wavelengths that showed both the highest correlation between reflectance and measured soil properties and were known for their physical interaction with the soil property concerned. Then, they applied these models using the reflectance of the airborne sensor. The 
authors demonstrated that the organic content, hygroscopic moisture and electric conductivity (EC) (all "surface" properties) can be predicted. Applying their models on a pixelby-pixel basis revealed the spatial distribution for each property. Some years after, Selige et al. (2006) were also able to predict the organic carbon $\left(\mathrm{C}_{\text {org }}\right)$, total nitrogen $\left(\mathrm{N}_{\text {tot }}\right)$, sand and clay content for 12 bare cropland fields covering 7000 ha within a Hymap (128 wave bands from 420 to $2480 \mathrm{~nm}$ ) flight line of $200 \mathrm{~km}^{2}$. Although it is generally assumed that there is a strong correlation between $\mathrm{C}$ and $\mathrm{N}$, the spectral models based on a multiple linear regression used distinctly different wavelengths for the two soil properties. This difference in spectral features is not in agreement with Rule 1.2, but fits within Rule 1.1 and 2 as referred to in chapter 2.1. Moreover, Selige et al. (2006) demonstrated that the maps of $\mathrm{N}_{\text {tot }}$ showed patterns caused by historical differences in land management dating from the period before land consolidation that were not visible in the $\mathrm{C}_{\text {org }}$ map.

Later, Stevens et al. $(2010,2012)$ predicted the SOC content in croplands of a N-S light strip $\left(420 \mathrm{~km}^{2}\right)$ in Luxembourg, as this soil property obeys Rule 1.1 and Rule 2 as referred to in Sect. 2.1. Data from the hyperspectral airborne AHS 160 sensor were used with 20 bands between 430 and $1030 \mathrm{~nm}$ and 42 bands between 1994 and $2540 \mathrm{~nm}$. The PLSR and PSR methods showed highest correlations between SOC content and reflectance in the visible ranges $(600-750 \mathrm{~nm})$, while the correlations in the SWIR were noisy for the PLSR and more consistent around $2100 \mathrm{~nm}$ for the PSR. The correlations around $700 \mathrm{~nm}$ and $2100 \mathrm{~nm}$ were also found by Ben-Dor et al. (2002) and confirm that the prediction models are based on spectral features.

Further, Gomez et al. (2012b) used the hyperspectral airborne Aisa-Dual sensor (260 hyperspectral bands from 450 to $2500 \mathrm{~nm}$ ) to map eight soil properties in a $300 \mathrm{~km}^{2}$ area in Northern Tunisia. They obtained good results for four properties (iron, cation exchange capacity (CEC), clay and sand) which followed Rules 1.1 or 1.2, and Rule 2 and incorrect estimations for four other properties $\left(\mathrm{CaCO}_{3}, \mathrm{pH}, \mathrm{SOC}\right.$ and Silt) which did not follow at least two out of the three rules. Given the large proportion of bare soil in this semiarid cropland environment, they were able to show a complex regional soil pattern reflecting the variations in lithology.

\subsubsection{Quality of the Predicted Soil Property Maps}

In this section, we are looking at the figures of merit of the predicted soil properties maps in terms of error measures $\left(\mathrm{R}^{2}, \mathrm{RMSE}, \ldots\right)$, the analysis of the spatial patterns in the predicted soil maps and the uncertainties analysis which could be associated with a quality analysis of predicted soil properties maps. Most papers on soil property mapping using imaging spectroscopy (cross)-validate the spectra of pixels registered by the airborne sensor against the conventional chemical analysis of soil samples collected in the same pixel. Table 1 shows examples of model performances including errors of prediction based on ground truth validation for the prediction of common soil properties maps using imaging spectroscopy. Different validation techniques are derived similar to chemometric approaches in the laboratory. Stevens et al. (2012), for example, examine different crossvalidation techniques and their impact on prediction accuracy. They further compare crossvalidation with real validation. This study shows that prediction accuracy of a soil property map derived from IS is also a question of the applied validation strategy.

However, in contrast to the laboratory where the mean error of prediction on each sample is the most important metric for the evaluation of the quality of the model, for soil maps there are more sources of uncertainty such as GPS position, atmospheric disturbance, 


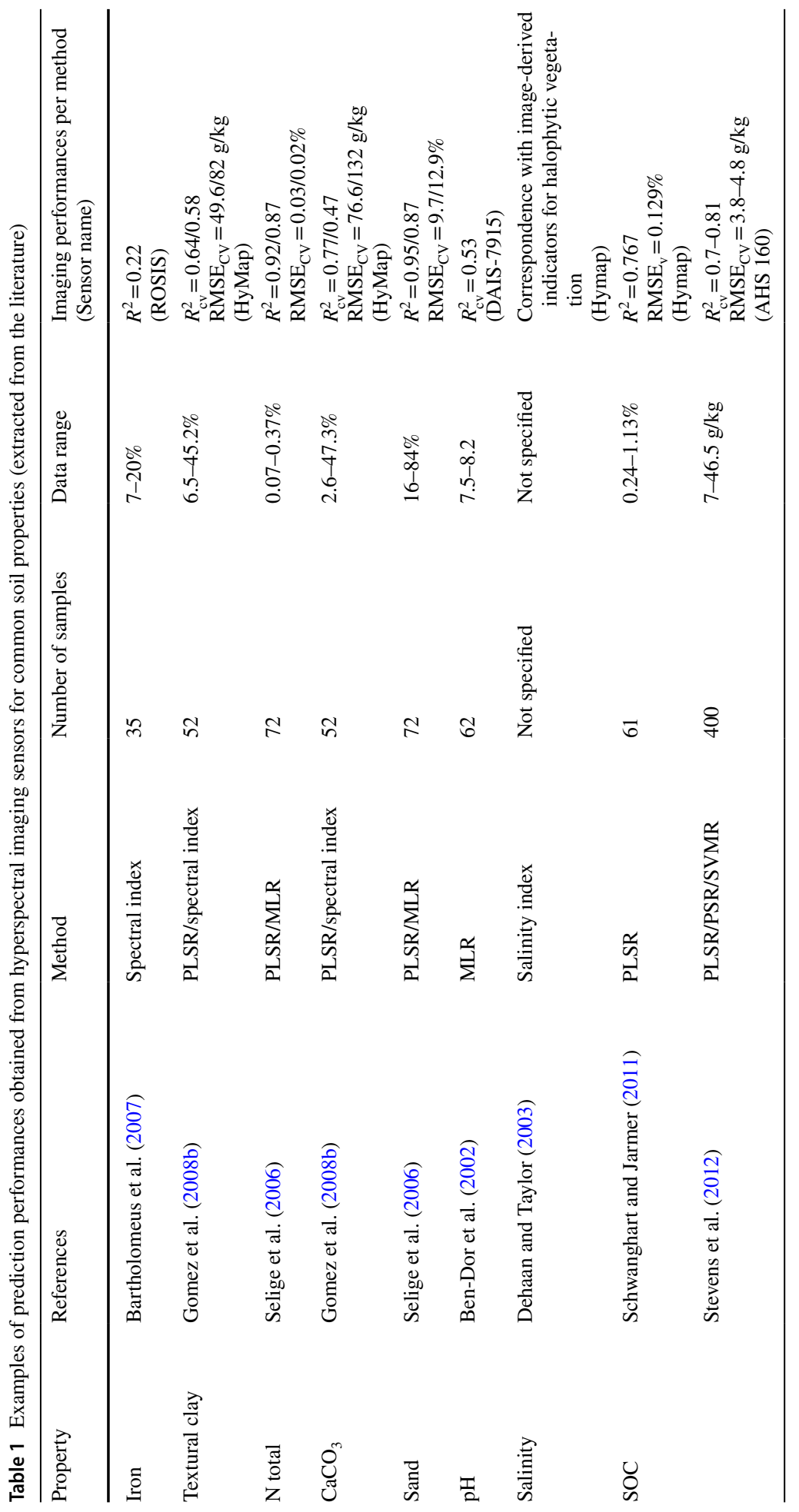


variation in soil surface conditions (e.g., moisture residue or roughness) and within-pixel variation of the soil property (see Sect. 4.2). Thus, spatial patterns of the soil property and uncertainty of the soil property maps are in addition to the model metrics important criteria to evaluate the quality of produced maps.

Imaging spectroscopy produces high-resolution (2-8 m pixels) maps of soil surface properties covering large areas that were hitherto not available. The clay maps of, e.g., Gomez et al. (2012b) cover an area of ca. $300 \mathrm{~km}^{2}$ in Northern Tunisia. Due to the low vegetation cover in these Mediterranean croplands, a large area could be mapped producing a clay map showing strong similarities to the geological map. Although extensive areas of bare cropland soil are rarer in temperate regions, Selige et al. (2006) and Stevens et al. (2010) also pointed to the spatial patterns that could be identified within or between fields. They related these patterns to historical differences in manure application reflected in the total Nitrogen $\left(\mathrm{N}_{\text {tot }}\right)$ maps or to rotations with temporary grassland reflected in the SOC maps that cannot be observed anymore after land consolidation. SOC patterns in fields covering the hill slope from the crest to the foot slope showed patterns related to erosion of $\mathrm{C}$ associated with the topsoil. Stevens et al. (2015) further demonstrated the importance of land management on SOC content. Their residual maximum likelihood model (REML) applied to the SOC map produced from the AHS160 flight over Luxembourg predicted that a field effect accounted for $48 \pm 8 \%$ of the variance in SOC content in a cluster of fields (Fig. 3).

The performance of the estimations obtained from regression models (MLR, PLSR, PSR, SVM...) is usually assessed with figures of merit such as the standard error of calibration, the standard error of prediction or the ratio of performance deviation, and these figures of merit evaluate the global model performance, as they are calculated during the model building and validation stages. A first evaluation of uncertainty that affects each prediction obtained by a hyperspectral airborne sensor has been realized by Gomez et al. (2015a). An evaluation of different types of uncertainties (i.e. variance of predictions) has been done: (1) prediction variance due to the regression model, (2) prediction variance due to the spectra and (3) prediction variance due to the interaction between these two effects, prediction variance due to differences between spectral predictors and spectral calibration samples. This paper showed that these prediction uncertainty maps may be used to better

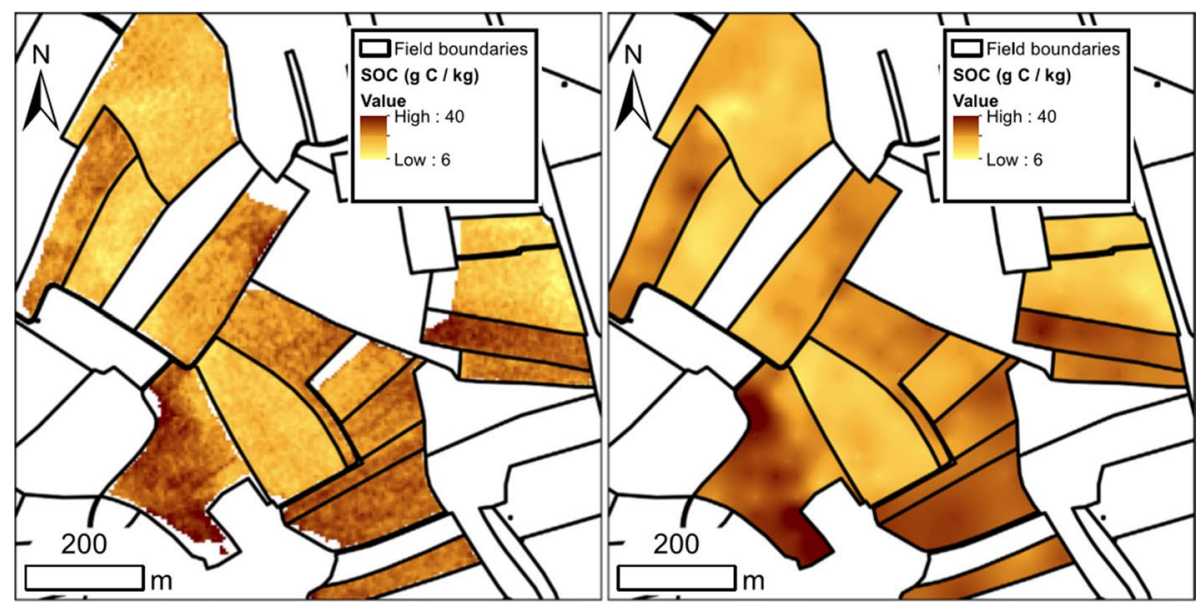

Fig. 3 Predicted SOC maps (left) from the AHS 160 campaign in Luxembourg (Stevens et al. 2010) and (right) using a residual maximum likelihood model (Stevens et al. 2015) 
characterize the quality of the soil properties mapping results, mask no-soil pixels and define the soil sampling and the calibration dataset.

\subsection{Soil Moisture}

Water is considered to be one of the most significant chromophores in the soil system (Idso et al. 1975; Stoner and Baumgardner 1981; Baumgardner et al. 1985; Hummel et al. 2001; Lobell and Asner 2002). Bowers and Hanks (1965) described the effect of soil moisture content on reflectance for the first time. The main effect is the decrease in reflectance with increasing soil moisture, and some spectral features are more affected than others. Dalal and Henry (1986) isolated the main differences in absorbance (log $1 /$ reflectance) and found them to be related to the variation in the moisture contents used across the 1100-2500-nm SWIR spectral region. Bishop et al. (1994) show the features directly associated with the $\mathrm{OH}$ group in the water molecule (at 1400 and $1900 \mathrm{~nm}$ ), and some are indirectly associated with the strong $\mathrm{OH}$ group in the thermal infrared region (around 2750-3000 nm) that affect the lattice $\mathrm{OH}$ in clay (at $2200 \mathrm{~nm}$ ) and $\mathrm{CO}_{3}$ in carbonates (at $2330 \mathrm{~nm}$ ). Ben-Dor et al. (1999) have noted the diminishing of the 2200-nm absorption feature in Ca-montmorillonite mineral at various relative humidity conditions. The highly sensitive 1900-nm region, a water $\mathrm{OH}$ combination band, showed an excellent nonlinear fit to the increase in water content. Muller and Decamps (2000) determined that the impact of soil moisture on reflectance could be greater than the differences in reflectance due to the soil categories, as it affects the baseline height (albedo) as well as several spectral features across the entire spectral range, as can be seen in Fig. $4 \mathrm{a}$.

(a)

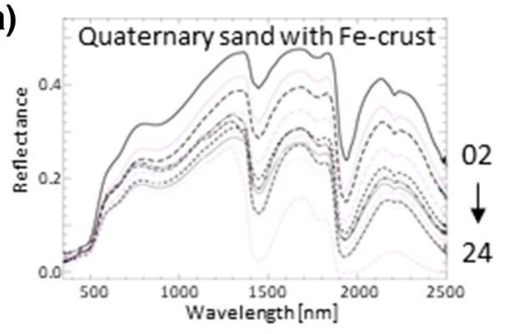

(b)

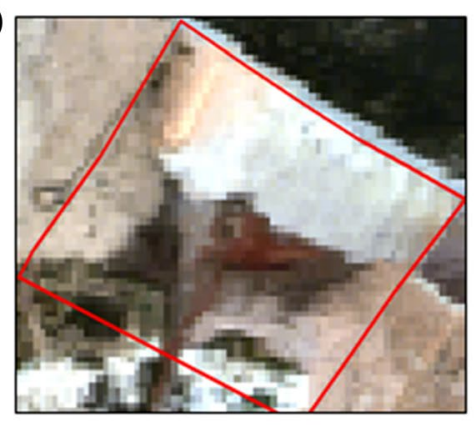

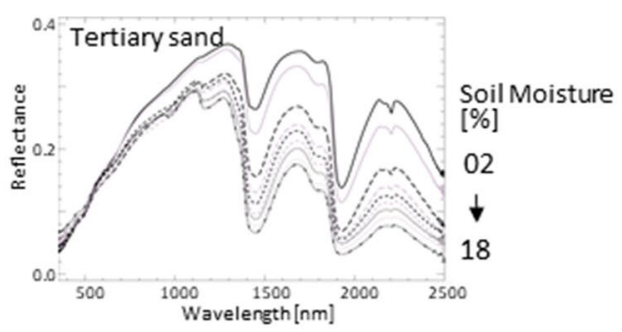

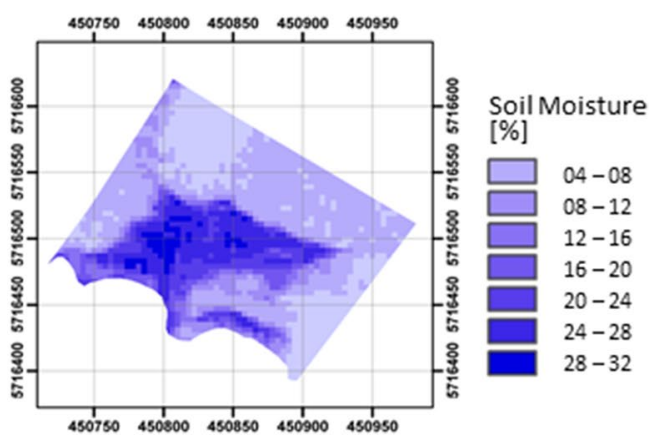

Fig. 4 a Influence of soil moisture on soil spectra from quaternary and tertiary sand; $\mathbf{b}$ determination of gravimetric water content based on HyMap imagery: HyMap RGB image (left) and modelled gravimetric soil water content (in \%) (right). Modified from Haubrock et al. (2008a, b) 
Several studies focused on the modelling of soil spectral reflectance and soil water content. Bach and Mauser (1994) were able to simulate the reflectance change of the soil spectra from dry to moist through the use of various water film depths related to moisture content. They combined the model of Lekner and Dorf (1988) for internal reflectance with the absorption coefficients from Palmer and Williams (1974) into Lambert's law (or Beer's law) to simulate the moist reflectance $R$ from the dry reflectance Ro by the exponential of the absorption coefficient and an empirically determined active thickness. They applied this process for predicting the water contents within an AVIRIS image of a partially irrigated field and a dark organic soil field in the Freiburg test site in Germany from the image pixel spectra of dry and moist soils. The active thickness and water absorption coefficients predicted the amount of the soil's water content to a high $R^{2}$ of 0.88 . Most recently, Bablet et al. (2018) have developed MARMIT, a multilayer radiative transfer model of soil reflectance to estimate soil water content that could be applied on imaging spectroscopy data in the laboratory, but not yet from remote sensing data.

Nowadays, robust spectral techniques to quantify and/or correct soil moisture content from surface reflectance exist that have been developed by several authors at the laboratory level and tested successfully on hyperspectral imagery (e.g., Bryant et al. 2003; Whiting et al. 2004a, b; Haubrock et al. 2008a, b; Fabre et al. 2015; Diek et al. 2019). The approaches range from spectral indices, exponential or Gaussian models, to geostatistical models. Whiting et al. (2004a) fitted an inverted Gaussian function centred on the assigned fundamental water absorption region at $2800 \mathrm{~nm}$, beyond the limit of commonly used instruments, over the logarithmic soil spectra continuum found with convex hull boundary points. The area of the inverted function, soil moisture Gaussian model (SMGM), accurately estimated the water content with coefficients of determinations $\left(R^{2}\right)$ of $0.94-0.98$ when samples were separated according to landform position (Spain) and salinity (USA). Using AVIRIS hyperspectral images of these soil regions in an air-dried status, they improved the abundance estimates of clay and carbonate abundance by $10 \%$ of the regression mean by including the SMGM area as a parameter in the empirical determination (Whiting et al. 2005).

Haubrock et al. (2008a, b) developed a successful simple approach termed the Normalized Soil Moisture Index (NSMI) based on the edges of the water band centred at $1900 \mathrm{~nm}$. It was developed in the laboratory and tested in the field for the best spectral prediction of soil moisture content taking into account the influence of different environmental factors, such as variable soil types, soil water profiles and the presence of soil crust and vegetation cover; and in remote sensing data based on hyperspectral imagery. The NSMI allowed the production of surface soil moisture maps, generated from HyMap airborne images (Fig. 4b), which were found to be highly correlated with the field moisture content measured at the time of the overflight (Haubrock et al. 2008b).

The NSMI and SMGM methods were successfully implemented in the soil mapping software tools HYSOMA and EnSoMAP (Chabrillat et al. 2011, 2016). Chabrillat et al. (2012) demonstrated that the two independent methods provide similar performances based on hyperspectral images for a same field, validated with ground data. Fabre et al. (2015) recognized that the water index soil (WISOIL) (Bryant et al. 2003) and the NSMI performed as good as the best soil moisture indices based on laboratory data. However, these indices are based on wavelengths located in or near the water absorption bands, which make them very sensitive to the quality of the atmospheric correction, and adapted indices were used by many authors (Fabre et al. 2015; Liu et al. 2003; Nocita et al. 2014). For that reason, Fabre et al. (2015), working on simulated spectral radiances at the sensor level, developed two additional soil moisture indices based on the wavelengths 2000-2200 nm 
that are less sensitive to atmospheric correction, but more sensitive to variations in soil texture. The two indices are the normalized index of the NIR and SWIR domain for soil moisture content estimation from linear regression (NINSON) and the normalized index of the NIR and SWIR domain for soil moisture content estimation from nonlinear regression (NINSOL). Diek et al. (2019) present a first attempt to reduce the effect of soil moisture (SM) variation on reflectance data of soils, independent of new laboratory measurements. SM was determined by a newly developed SM index, similar to the existing NINSOL index, and was successfully applied to both field and airborne spectroscopy data, with $R^{2}$ of 0.75 and 0.59 , respectively.

Nowadays, surface water content in soils can be cautiously estimated based on spectral reflectance, providing topsoil information that is not available at this scale through other systems and that could complement in bare areas the global estimates of near-surface soil moisture provided by microwave satellites. However, completely correcting the effect of soil water content on the reflectance mineral and organic band depths for an improved retrieval of other soil covariate continues to elude us. Further work in reconstructing the spectra will combine the spectral relationship of water content and soil components based on the physical nature of the materials and photon absorptions.

\subsection{Soil Crust}

Soil crust refers to a thin layer on top of the soil surface that is exposed to solar radiation and hence to the remote sensing sensors (Agassi et al. 1981). The arrangement of the upper thin layer of the soils, which actually formed the crust, is controlled by biogenic/organic process as well as by mechanical forces. Depending on the processes dominating the crust formation, soil crusts are termed biological/organic or physical. Biological/organic crusts are formed by communities of microorganisms that live on the soil surface, whereas physical crusts are formed by physical impact such as that of raindrops.

Biological soil crusts, or biocrusts, are generated from live materials, such as complex communities of cyanobacteria, algae, lichen and mosses. Biocrusts modify the surface spectral response and can mask soil spectral properties (Weber et al. 2008). For recent reviews on the effect of biocrusts on soil spectral signal and the biocrust mapping methods based on optical remote sensing, we refer to Escribano et al. (2017) and Weber and Hill (2016). In particular, it was shown that many studies referred to biocrust spectral traits at the laboratory and field scale, and approaches based on hyperspectral indices or spectral mixing analyses were developed to spectrally identify biocrusts or for biocrust surface cover quantification. For example, Weber et al. (2008) and Chamizo et al. (2012) developed two biocrust mapping hyperspectral indices that were used to map cyanobacteria-dominated biocrust in Soebatsfontein (South Africa) and in southern Spain, respectively, based on hyperspectral imagery. With this, the subtle spectral differences between sparse vegetation, bare soil and biocrust could be identified. Nevertheless, important classification errors were observed in heterogeneous areas where each pixel is covered by a mixture of semiarid vegetation, bare soil and biocrusts (Alonso et al., 2014). Similarly, Hill et al. (1999) and Rodríguez-Caballero et al. (2014) used spectral unmixing methods to successfully quantify the amount of biocrust coverage within a pixel based on hyperspectral imagery in the Nitzana region (Israel), and in El Cautivo area (Spain). Some issues were observed in discriminating biocrusts in the areas dominated by vegetation, and an improved discrimination could be obtained by the prior definition of areas into different land units. 
Karnieli et al. (1999) demonstrated that cyanobacteria provide unique spectral features on sand dune at the Negev area in Israel just as decomposed OM, whereas Ben-Dor et al. (1997) demonstrated that the same fresh OM may hold different spectral fingerprints based on the decomposition stage at the laboratory level. One of the important organic crusts that affect hydraulic conductivity of the thin surface layer is the OM with hydrophobic characteristics. This crust dramatically diminishes the infiltration rate of water to the soil profile and hence increases erosion and soil degradation and loss. Recently Ben-Dor et al. (2017) demonstrated a significant correlation between reflectance properties of the soil crust measured in the field by using the SoilPRO apparatus and hydrophobicity field values as measured by the water droplet penetration time (WDPT) method over orchards trees soils, by thus demonstrating a possible application based on future IS data.

The soil physical crust mostly refers to the rearrangement of soil particles as a result of the raindrop energy which disintegrates soil aggregates into a microstructure where fine particles are exposed at the top surface facing the Sun, and coarser particles are found in the soil profile. In general, the factors leading to the formation of the structural crust (raindrop energy driven) are a combination of the kinetic energy impact of raindrops and the level of stability of the soil aggregates (Agassi et al. 1981, 1985). The structural crust is generated within minutes and significantly reduces the soil infiltration rate (IR). The crust hydraulic conductivity (HC) is lowered by a few orders of magnitude compared to the underlying soil (McIntyre 1958; Benyamini and Unger 1984). As the structural crust affects physical properties of the soil and can be observed by significant colour changes on the soil's surface, spectral information, and especially on the surface, may be an excellent tool to monitor its status. To that end, spectral differences observed in the structural crust demonstrated that the upper microstructure is composed of fine texture with some significant increase of the clay fraction (Ben-Dor et al. 2004). Whenever the HC of the crust is lower than the rainfall intensity, ponding, runoff and soil erosion will follow crust (Agassi et al. 1981, 1985). These processes may further change the upper soil surface properties as seen by hyperspectral sensor pointing on erosion, deposition and sedimentation effect over the soil in question.

Monitoring the soil crust condition is essential for the proper management of soils, from both an agricultural and land degradation perspective, and much work toward this end was done using reflectance spectroscopy at the laboratory level. Several studies demonstrated that reflectance spectroscopy can provide a valuable method for assessing the condition of the soil crust and estimating the related problem (Demattê et al. 2004; Goldshleger et al. 2001; De Jong 1992; Eshel and Levey 2004; Ben-Dor et al. 2004). More studies toward this direction by Goldshleger et al. $(2002,2004)$ and BenDor et al. (2003) demonstrated that the reflectance properties of soils can be an indicator for temporal processes that evolve on the soil surface due to runoff and erosion that were driven by the physical crust formation, based on laboratory experiments. An ambitious and very interesting study to upscale the physical soil crust spectral properties from the laboratory (rain simulator) to the field and to remote sensing was done by Ben-Dor et al. (2004). In this study, loess (agricultural) soils from Israel were examined for the soil crust at the laboratory which was then applied to the AisaEAGLE sensor to generate a soil infiltration map on a pixel-by-pixel basis (Fig. 5). Validation in the field confirmed the results and suggested that this idea could be extrapolated to other areas in order to prevent soil degradation processes by water erosion. 


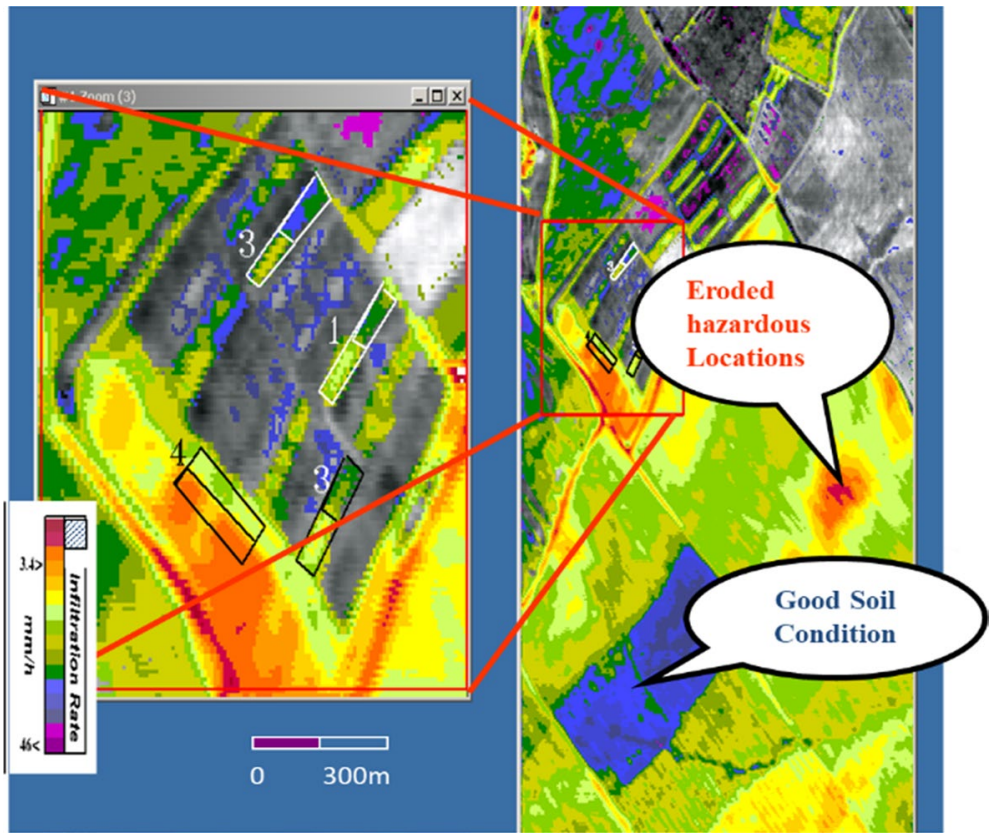

Fig. 5 Mapping of soil infiltration on a pixel-by-pixel basis derived from AisaEAGLE hyperspectral imagery (after Ben-Dor et al. 2004)

\subsection{Soil Erosion and Degradation}

Soils are considered non-renewable resources which have a limited extent, are unequally distributed geographically, are affected by degradation due to inappropriate land management and use, but are essential to terrestrial life and human well-being (Lal 2015). Adverse climatic conditions and inappropriate human activities on land use can lead to a loss of soil quality and as a consequence to degradation of soil properties (Stolte et al. 2016). Soil degradation is a change in the soil health status resulting in a diminished capacity of the ecosystem to provide goods and services for its beneficiaries (FAO and ITPS 2015). Degraded soils do not provide services according to their original potential in an ecosystem. Soil erosion, salinization, desertification and pollution are some of the main processes affecting soil degradation, which occur over space and time. Soil erosion is a land degradation process which is often found in cultivated environments due to natural processes (e.g., climate events) and accelerated by human activities (e.g., extensive tillage). Tillage-induced soil erosion brings about the progressive removal of soil horizons and the corresponding accumulation of soil materials at the slope (Previtali 2014). Furthermore, soil erosion may reduce crop production potential, lower surface water quality and damage tile drainage systems (Toy et al. 2002). Erosion is associated with about $85 \%$ of land degradation in the world, causing up to a $17 \%$ reduction in crop productivity (Oldeman et al. 1990). In Europe, soil loss is estimated at $2.46 \mathrm{tha}^{-1}$ year $^{-1}$ with a total loss of $970 \mathrm{Mt}$ annually within agricultural, forests and semi-natural areas that are most affected by erosion (Panagos et al. 2015). To counteract land degradation, improvements are needed in methods of managing and monitoring of 
soil resources (Eswaran et al. 2001). Mapping the extent of degraded lands and monitoring the situation in erosion-threatened soils are important in order to achieve the sustainable development goals set out by the United Nations. This implies sustainable management practices, soil conservation, restoration of degraded soils and improved land management practices (Ussiri and Lal 2018).

Remote sensing technologies can provide the necessary information for carrying out the assessment and monitoring of soil degradation processes such as soil erosion (Shoshany et al. 2013). Within the Vis-NIR and SWIR spectral regions, inorganic and organic components such as clay minerals, soil organic matter (SOM), iron oxides or calcium carbonate $\left(\mathrm{CaCO}_{3}\right)$ interact with the electromagnetic radiation and produce characteristic absorption features in soil reflectance spectra that can be used to identify soil properties when soils are exposed at the surface and vegetation cover is low (Chabrillat et al. 2002; Nanni and Demattê 2006; Stevens et al. 2013). Hyperspectral Vis-NIR-SWIR imaging has proven to be a promising tool to characterize and map topsoil properties (Chabrillat et al. 2002; Stevens et al. 2013; Schmid et al. 2016). This is especially relevant within Mediterranean regions where the exposure of bare-soil surfaces is common due to sparse vegetation cover and management practices such as leaving fields fallow (Bartholomeus et al. 2007; Gómez et al. 2012). Nowadays, it is well established that the quality of hyperspectral data is very important for quantitative assessment of key soil properties (Ben-Dor et al. 2009), and the soil properties determined by IS can be related to soil degradation processes. At present, there are a number of hyperspectral airborne sensors available worldwide such as HyMap (www.hyvista.com), HySpex (www.hyspex.no) or Aisa (www.specim.fi) that are suitable for soil studies. Furthermore, data from satelliteborne hyperspectral sensors such as Hyperion and CHRIS-PROBA exist and could be implemented to determine common soil properties such as clay minerals, iron oxide and calcium carbonate content. These two sensors were operating since 2000 and 2001, respectively, but the Hyperion sensor was decommissioned at the beginning of 2017. Then, as summarized in Sect. 1, there are a series of upcoming hyperspectral satellite-borne sensors that will be ideal for the monitoring of surface soil properties and related soil degradation.

Studies on soil properties and conditions have been carried out using data from field spectroradiometer, hyperspectral and multispectral airborne and satellite-borne sensors to determine the spatial distribution of surface soil properties and soil erosion on a local to regional scale (Ben-Dor et al. 2006; Chabrillat 2006; Corbane et al. 2008; Hill and Schütt 2000; Schmid et al. 2008; Vrieling et al. 2008). This approach is of interest when studying soil erosion as given in the example from Schmid et al. (2016). Here, hyperspectral data supported by morphological and physicochemical ground data were able to identify, define and map soil properties that could be used as indicators to assess soil erosion and accumulation stages (SEAS) in a Mediterranean rainfed cultivated region (Camarena, near Madrid, Spain). These properties were characterized by different soil horizons that emerge at the surface as a consequence of the intensity of the erosion processes, or the result of accumulation conditions. Therefore, selected sites representing different soil properties for the SEAS were used to train the SVM classifier to obtain their spatial distribution (Fig. 6).

\section{Challenges and Gaps}

There is a known decrease of soil properties' prediction performances from laboratory to airborne imaging spectroscopy that has been demonstrated by several authors. This performance decrease is due to the combination of several effects such as differences in 

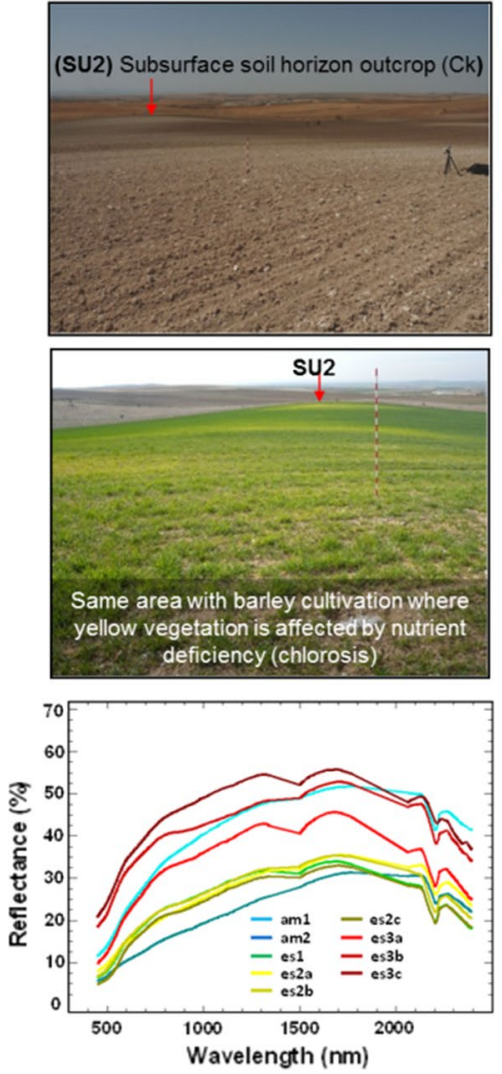

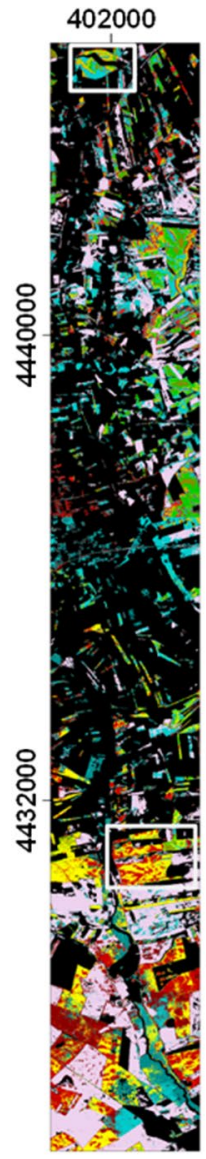

Stages

am1

am2

es1

es $2 a$

es $2 b$

es $2 c$

es3a

a $33 \mathrm{~b}$

es3c

$\mathrm{npV} \longrightarrow$ Dry vegetation

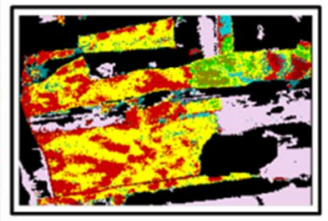

N

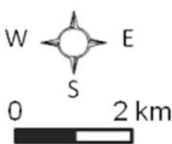

Accumulation stages

Erosion

stages

Fig. 6 Mapping of soil erosion and degradation stages derived from AisaEAGLE and AisaHAWK hyperspectral imagery. Modified from Schmid et al. (2016)

the measurement conditions (sensors performances, different acquisition altitudes, optical angles and lighting conditions), target structure and composition differences (laboratory soil samples are dried, crushed and sieved while hyperspectral airborne targets are natural surfaces with heterogeneous surface temperatures and mixture in the field of view, moisture levels and roughness). The three main factors affecting the soil reflectance and so the model prediction accuracy have been assigned to (e.g., Stevens et al. 2008; Ben-Dor et al. 2009; Lagacherie et al. 2008): (1) the atmosphere; (2) a low signalto-noise ratio of the imaging sensor data and (3) disruptive factors affecting the soil surface (partial vegetation cover, moisture, crust). Additionally, the availability of soil data, linked to the ad hoc need for calibration data, is a global challenge for the modelling of soil properties. Below, we present a summary of the main challenges and avenues of future research for global soil mapping and monitoring applications based on imaging spectroscopy data. They are grouped into three categories of challenges associated with different sensors, platforms, and reflectance data preprocessing, different surface conditions and different methodologies used for soil properties extraction. 


\subsection{Sensors, Platforms and Reflectance Data Preprocessing}

Imaging spectroscopy data in the Vis-NIR-SWIR may be acquired by three types of platforms: unmanned aerial vehicles (UAV), satellite, and airborne which is the most common. Hyperspectral cameras that can be mounted on UAV are of recent manufacture and cover only the VNIR spectral domain. Although SWIR cameras for UAVs still need to be optimized in terms of size and weight, and the auxiliary devices needed during flight have to be miniaturized, first models are just becoming available (e.g., HySpex Mjolnir S-620 from Norsk Elektro Optikk, NEO). The UAV low altitude allows a high spatial $(<50 \mathrm{~cm})$ and temporal resolution which bears a very high potential for applications in precision agriculture at the field scale, with cost-effective and flexible deployment capability regarding meteorological conditions. The performance of soil properties estimation by hyperspectral UAV sensors has still to be evaluated. A first initiative of soil mapping by a UAV platform focused on a VNIR multispectral UAV sensor for organic carbon content estimation and gave encouraging results (Aldana-Jague et al. 2016).

Only one hyperspectral satellite sensor covering the full Vis-NIR-SWIR has been in orbit from 2000 to early 2017, the Hyperion sensor aboard EO-1 satellite, which provided a spatial resolution of $30 \mathrm{~m}$, a spectral resolution of $10 \mathrm{~nm}$, a medium-low signal-to-noise ratio and a swath of $7.5 \mathrm{~km}$ (Folkman et al. 2001). Few studies were carried out on soil properties mapping by Hyperion data. Gomez et al. (2008a) and Lu et al. (2013) mapped SOC content with moderate performances using Hyperion data. Lu et al. (2013) mapped total phosphorus and $\mathrm{pH}$ with moderate performances, whereas the cation exchange capacity prediction exhibited low efficiency. More hyperspectral Vis-NIR-SWIR satellite sensors are planned to be launched within the next years, as already noted earlier in this paper, with high radiometric quality (higher signal-to-noise ratio). Below, we review the impact of several issues related to sensors and data preprocessing on soil properties mapping.

\subsubsection{Impact of Spatial Resolution}

Gomez et al. (2015b) studied the sensitivity of the clay content prediction with respect to the degradation of the spatial resolution on hyperspectral Vis-NIR-SWIR airborne data. Their results showed that the spatial resolution impact on clay content mapping may depend on both the spatial structure of the studied soil property and the size of the studied fields in cultivated areas. In their study area characterized by small fields (around $0.56 \mathrm{ha}$ ) and strong spatial structure of clay due to short-scale successions of the parent material, clay mapping performances using hyperspectral data were accurate with an $R^{2}$ of 0.74 at $5 \mathrm{~m}$ resolution and 0.66 at $30 \mathrm{~m}$ resolution (Fig. 7). Therefore, even over small-scale agriculture fields, the spatial resolution planned for future PRISMA, EnMAP, SHALOM and HypXIM (Lefèvre-Fonollosa et al. 2016) satellite sensors seems to be promising for clay content mapping.

\subsubsection{Impact of Spectral Resolution}

Using laboratory spectroscopic Vis-NIR-SWIR data, Castaldi et al. (2016) obtained accurate clay prediction performances using spectra with bandwidths from 10 to $160 \mathrm{~nm}$. In addition, Adeline et al. (2017) obtained accurate clay prediction performances using laboratory spectra with bandwidths of up to $200 \mathrm{~nm}$. Adeline et al. (2017) observed that (1) 


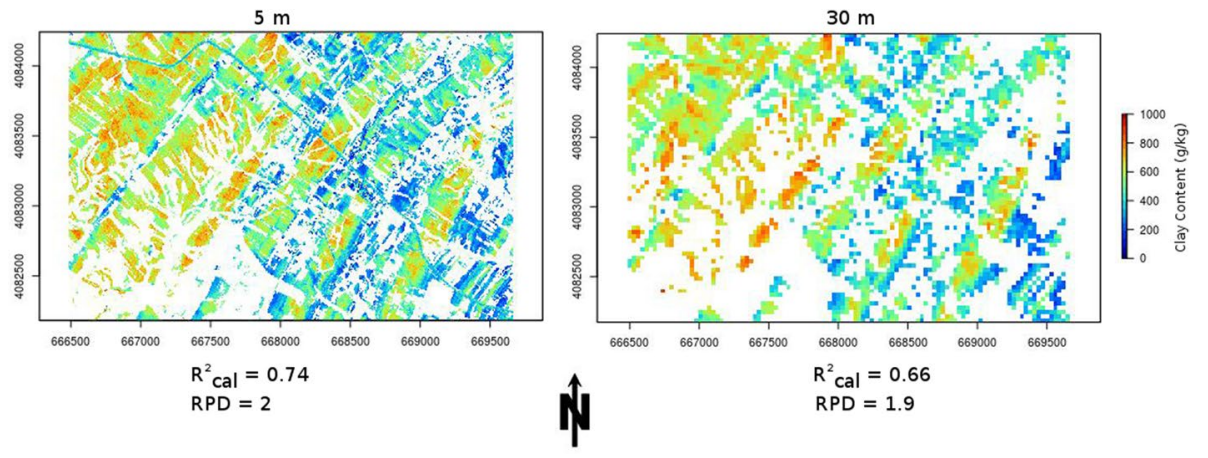

Fig. 7 Sensitivity of clay content prediction with respect to degradation of the spatial resolution on hyperspectral Vis-NIR-SWIR airborne data. Extracted from Gomez et al. (2015b)

soil properties with large and pronounced spectral features (e.g., iron) are only slightly impacted by a decrease in spectral resolution and (2) soil properties with no spectral features (e.g., pH) may be strongly impacted by a decrease in spectral resolution, and this impact may be reduced if these soil properties rely on the beneficial effects of correlations with soil properties and with spectral features (e.g., correlation between $\mathrm{pH}$ and iron).

\subsubsection{Impact of Atmospheric Attenuation}

Rectification of atmospheric attenuation is critical in the IS domain, since if it is not properly done, it may influence the spectral signals that mistakenly can be assumed as part of the soil chromophores and increase noise in the signal. The issue of precise atmospheric correction has been studied by many researchers, and a combination of radiative transfer modelling and empirical methods is found to solve most of the past problems. In recent publications, the sensor radiometric instability problems as well as new and simple indicators to judge and correct systematic effects in airborne IS sensors have been developed by Brook and Ben-Dor $(2014,2015)$. Also, Gomez et al. (2015b) studied the sensitivity of the clay content prediction due to atmospheric effects on hyperspectral Vis-NIR-SWIR airborne data and simulated satellite data. They observed that when a correct compensation of atmosphere effects was performed using an inverse radiative transfer model, only slight differences were observed between clay content maps obtained using airborne imagery and simulated satellite imagery.

\subsection{Soil Surface Conditions: Soil Moisture and Soil Roughness, Partial Vegetation Cover}

Short-term variations in soil surface conditions due to meteorological conditions or land management practices such as ploughing and greening of the crop fields to prevent soil erosion have all an effect on soil reflectance. Soil reflectance decreases with increasing soil moisture and with increasing soil roughness, and nonlinear effects on soil spectral features are also observed. The increase in partial vegetation cover changes completely the shape of soil spectral reflectance. In turn, variations such as in soil moisture, soil surface roughness and vegetation cover have a strong impact on the quality and accuracy of the prediction 
of the soil properties. Here, we describe the latest developments in the assessment of the impact of these effects, and on the development of procedures to take into account or correct for these effects, in the frame of soil mapping and monitoring applications.

\subsubsection{Soil Moisture}

The impact of soil moisture on the surface reflectance and examples of the successful quantification of topsoil gravimetric water content based on imaging spectroscopy data are presented in detail in Sect. 3.2. Mainly, three types of approaches based on empirical models are commonly used for SM estimation: spectral indices (Haubrock et al. 2008a, b; Fabre et al. 2015), exponential or Gaussian spectral models (Bryant et al. 2003; Whiting et al. 2004a; Liu et al. 2015) and geostatistical models (Fabre et al. 2015). The use of these methods for the inverse retrieval of the impact of soil moisture on the surface reflectance is not obvious as they need a priori knowledge or field data for calibration or need to be tested for wider applications in the case of the spectral indices. Several authors (Bogrekci and Lee 2006; Minasny et al. 2011; Castaldi et al. 2015; Ge et al. 2014; Liu et al. 2015) focused on the development of accurate procedures to correct or reduce the effect of soil moisture on reflectance data. Nevertheless, these studies are not commonly applicable on airborne IS. They are complex and focus on only one single soil property, or they need additional laboratory analyses that make them not yet adequate for remote sensing applications. Very recent further developments, however, use physical modelling (Bablet et al. 2017) or an adapted soil spectral index (Diek et al. 2017a) to successfully derive bare-soil spectra corrected for soil moisture and soil roughness effects. Furthermore, Diek et al. (2017a) were able to apply it on APEX imagery and validate the values against laboratory dry-soil spectra, showing the potential for further application in soil mapping based on airborne IS data.

\subsubsection{Soil Roughness}

Although there is a full literature on the categories of soil roughness, on the effect of variable soil roughness on reflectance data and on the BRDF simulation of rough soil (shown in Sect. 2.2), the applicability of these studies for the correction of soil roughness effects on airborne imaging spectroscopy data is not yet resolved. Several studies focus on the decrease of the effect of soil roughness on reflectance data (Wu et al. 2009; Croft et al. 2014; Denis et al. 2014; Ji et al. 2015). But they are not applicable to remote sensing spectroscopy applications due to their complexity, or limitations in terms of not including all categories or all aspects of soil roughness effects. Nevertheless, one can cite the recent efforts of Bablet et al. (2017) and Diek et al. (2017a) for the correction of the combined effects of soil moisture and soil surface roughness on soil reflectance and the potential for application on airborne IS data (Diek et al. 2017a).

Current studies on the impact of soil crust property on soil reflectance demonstrated that the upper soil surface and the undisturbed surface properties are actually seen by the IS sensor. The soil proxy analysis that is being developed using soil spectral libraries is problematic to be directly implemented at the airborne scale to the hyperspectral sensors, and therefore, the soil crust remains one of the properties that needs to be spectrally modelled in order to combine laboratory and field to the airborne domains. This is mainly because the soil spectral library is sampled within $0-5 \mathrm{~cm}$ and may disturb the soil upper surface. Accordingly, the reflectance seen by the IS sensor is not the reflectance that is used to generate the proxy model and thus the spectral library model cannot be directly used for the IS 
data. A precaution then has to be taken where soil crust may evolve in the soil measured by IS sensors. Nonetheless, as a generic model can be obtained from different soils, developing a soil physical crust spectral library can be an added value to the current soil spectral libraries and should be further studied, developed and used.

\subsubsection{Partial Vegetation Cover}

Soils are not bare in most cases while vegetation, organic and inorganic debris are partially or completely covering the soil in question. According to Bartholomeus et al. (2007), vegetation cover of more than $20 \%$ prevents accurate soil properties estimation. In situations with partial soil exposure variations, Rodger and Cudahy (2009) showed that the depth of the clay absorption feature can be attributed to varying clay contents as well as differing proportions of soil exposure. Bartholomeus et al. (2011) show that with only a few per cent fractional maize cover, the accuracy of a PLSR-based SOC prediction model drops dramatically. As a result, most studies on soil properties mapping focus on bare or semi-bare areas for soil properties prediction, associated with natural bare areas or with crop areas just after harvesting or just before or after sowing. Then, two-step approaches are mostly used for operational soil properties mapping based on imaging spectroscopy, first removing the pixels with high vegetation cover and then applying soil algorithms in bare and semi-bare areas. For example, Chabrillat et al. $(2011,2016)$ in the HYSOMA and EnSoMAP soil mapping tools derive green and dry vegetation cover based on vegetation indices and develop a soil dominant pixel image on which the soil mapping tools will be applied. The use of multi-temporal data composites from airborne imaging spectroscopy (e.g., Gerighausen et al. 2012; Diek et al. 2016) is advocated to develop larger bare-soil maps. Experience in this domain from multispectral satellites (e.g., Blasch et al. 2015; Rogge et al. 2017; Diek et al. 2017b; Demattê et al. 2018) might help to develop in future such strategies based on hyperspectral satellites.

Simultaneously, intensive research is performed on the reduction of the impact of vegetation cover in mixed soil-vegetation spectra. Many studies look at the removal of vegetation component in the soil reflectance spectrum by spectral modelization. Bartholomeus et al. (2011) used the residual spectral unmixing (RSU) to filter out the influence of maize and could do SOC mapping with accuracies comparable to studies performed on baresoil surfaces. Then, the "double-extraction" approach was introduced by Ouerghemmi et al. (2011), which consists of a first extraction of an estimated soil spectrum from mixed Vis-NIR-SWIR spectra using a semi-blind source separation method and a second extraction of the soil property content from the estimated soil spectrum, using the PLSR method calibrated over bare-soil pixels. First results, obtained by Ouerghemmi et al. (2016) were encouraging, as this "double-extraction" approach using a nonnegative matrix factorization method for the second extraction and applied to HyMap Vis-NIR-SWIR imaging data, allowed to map clay content over more than $63 \%$ of study area $(59.5 \%$ of semi-vegetated area and $3.5 \%$ of bare soil). The nonnegative matrix factorization method was also tested by $\mathrm{Li}$ et al. (2017). They demonstrated that this method is feasible to discriminate the vegetation signals from the soil backgrounds in varying densities ranging from 14 to $94.6 \%$. Although implemented to retrieve a pure vegetation spectrum from every pixel, the other way can be done as well, i.e. retrieve soil spectra out of dense vegetation coverage. Similarly, Kuester et al. (2017) use the HySimCaR (hyperspectral simulation of canopy reflectance) model (Kuester et al. 2014) to generate virtual crop landscapes with variable type of cover (early green phenological stages and dry stubbles), fractional cover and different 
soil backgrounds with varying SOC and textural composition and to assess the impact of vegetation cover on soil spectral features. They show that the impact of vegetation cover is variable depending on the soil background, and furthermore, correction procedures are proposed that need to be further tested and validated in wider context.

\subsection{Methodologies for Soil Properties Extraction}

Two intrinsic limitations in the use of IS for soil mapping are that (1) the sensor sees only the upper surface (about $50 \mathrm{~mm}$ ) and thus cannot do a pedogenic mapping where the entire soil profile is needed in order to classify the soil order and (2) the high costs and complexity of commonly used airborne campaigns and associated data analyses and processing hinder an extensive use of the technology. It requires expensive sensors, flight hours, professional manpower, expert knowledge and a sophisticated infrastructure that cannot be regularly used. This requires that the problems that IS should solve are of high importance to the end users and that IS can provide a better view and economic benefits than the traditional methods such as wet chemistry. As such, IS can pick important surface properties that evolve on the soil surface such as OM, surface moisture, dust accumulation, soil deposition or erosion, physical or biogenic crust sand compaction.

With the upcoming availability of the next generation of spaceborne imaging spectroscopy sensors, an important issue is linked with the development of accessible methods for the generation and delivery of soil image products to the geoscience community. Established techniques for soil property determination from airborne imaging spectroscopy are mainly either based on multivariate statistical methods such as PLSR and SVM or based on the direct analyses of the spectral reflectance signal such as spectral feature analyses (measurements of spectral features, slopes, Gaussian modelling). Both types of methodologies present different conditions of use and a priori expected performances which make them use on a per case basis (e.g., see analyses of Chabrillat et al. 2014; Escribano et al. 2017), and in all case both need ground data for quantitative soil properties mapping. Although PLSR is by far the most used method in quantitative soil spectroscopy, direct reflectanceanalyses methods present the advantage that they are more generic and can be implemented on an operational basis in software interfaces, and repeatability and robustness of the soil prediction models can be better provided. Furthermore, such methods allow fully automatic derivation of semi-quantitative soil maps that do not require the need for ground data and do not require expert knowledge. For example, methods based on the direct analyses of spectral reflectance (absorption band analyses, slopes, spectral indices, Gaussian modelling) were implemented in the HYSOMA and EnSoMAP software interfaces for soil mapping (e.g., Chabrillat et al. 2011, 2016). HYSOMA (Fig. 8), developed originally as demonstrator of end-to-end processing chain for the delivery of soil maps to the users and provided since 2012 on the Web for free as stand-alone interface, stands nowadays with worldwide $>130$ users and demonstrated the need for such tools. Also, further implemented as EnSoMAP in the EnMAP-box tool (Van der Linden et al. 2015), it shows the potential of such soil products to be commonly provided for future soil users of upcoming IS spaceborne imagery.

An important methodological issue in quantitative soil properties mapping based on IS is linked with the need for ad hoc ground truth data for model calibration and validation, and standards and protocols for ground data acquisition. Since the pixel size cannot really represent point measurements, at least $3 \times 3$ pixels have to be averaged for both spectral ground truth measurements and chemical analysis. Different strategies for soil sampling at the scale of the IS sensor are developed that are mostly similar in their concept but also 

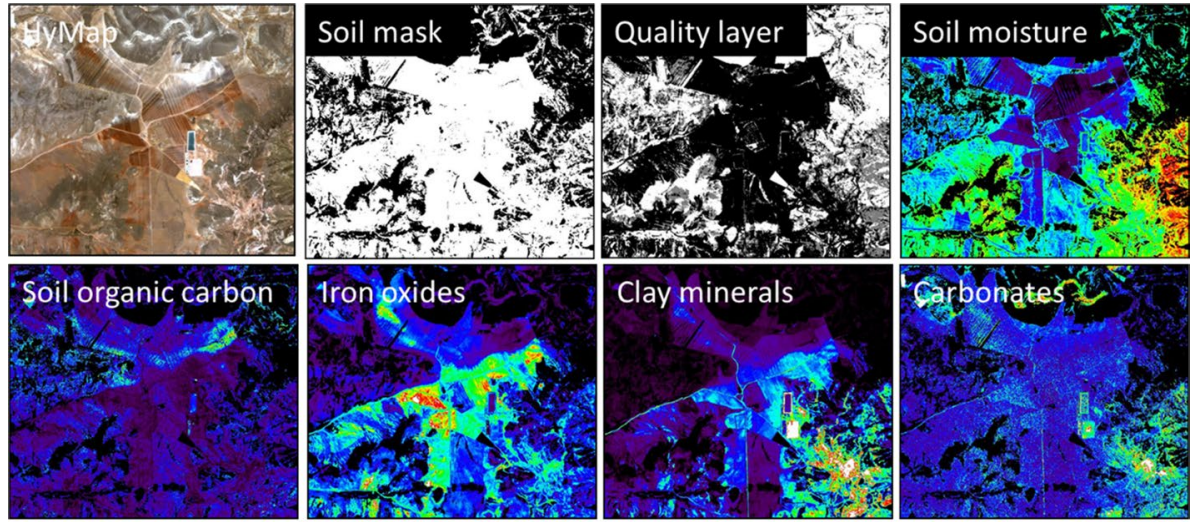

Soil properties mapping (\%)

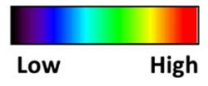

Fig. 8 Operational semi-quantitative soil properties mapping derived from airborne HyMap hyperspectral imagery. Map outputs were created using the HYSOMA software (Chabrillat et al. 2011, 2016)

with differences such as in Stevens et al. (2013), Schmid et al. (2016), or Castaldi et al. (2019). Overall, in most reviewed studies that successfully applied the quantitative chemometric approach to IS data, it was found that these studies lean heavily mostly on homogeneous areas (in terms of parent material and soil-forming processes "soilscapes"). Ground truth measurement and sampling to represent pixel in the imagery would need to sample area in a standard way that will cope for all the issues previously mentioned such as representativity of the sampled area, spatial resolution, bare and dry area (not affecting the soil surface and controlling the BRDF effects). Apparently, such an approach is not yet available, whereas Ben-Dor et al. (2017) developed an apparatus that is capable of maintaining a very stable and standard spectral measurement of soil in the field without relying on the natural illumination and atmosphere conditions while overcoming the above-mentioned effects.

A novel strategy to overcome the need for the acquisition of large sets of ground measurements is to consider the use of large soil databases and/or legacy soil data. Although most of the published research nowadays concerns the calibration of prediction models using local soil datasets, recently this strategy has attracted the attention of many scientists due to the higher potential for large-scale soil mapping and for reduction of the soil sample collection cost and time. Gomez et al. (2016) showed that using legacy soil data collected over and/or around a large area in the Mediterranean region, they could calibrate a clay spectral index and derive topsoil clay content maps based on Aisa-Dual IS data. Furthermore, a possible way to solve the issues related to the collection of a representative ad hoc local dataset is the use of large soil spectral libraries. Castaldi et al. (2018a, b), exploiting the potential of the EU-wide LUCAS soil database described in, e.g., Toth et al. (2013), proposed a new approach based on uniform analysis protocol and PLSR models for SOC mapping in croplands in Europe. They demonstrated the capability to be applied for laboratory prediction of SOC but also for quantitative SOC mapping based on APEX hyperspectral imagery.

The challenges posed by the use of multivariate statistical models for soil mapping raise questions as to what extent can the quantitative models provide reliable and useful 
information, transferability of the models, dependency on the availability of soil data, or whether is it always possible to adopt the chemometric strategy for real IS remote sensing data regarding the difference between airborne and laboratory spectroscopy. In general, it has been shown that this technique can be used if the soil samples preserved the exact surface properties seen by the sensor but then, only some soil properties can be modelled (e.g., crust dust, OM and surface moisture). If the soils are ploughed and the soil surface is broken to represent the $0-5 \mathrm{~cm}$ that is usually measured in soil spectral libraries, it is more likely that the laboratory reflectance measurements will be comparable to the soil measurements from the air and space. Furthermore, in the frame of the upcoming availability of high-quality spaceborne IS data at global scale covering the whole Earth, an additional challenge linked to the transfer of the soil spectral models from regional to global scale is with respect to the different global soil regions and resulting implications for the empirical and statistical modelling. In that regard, extensive efforts are being devoted to the development of global soil databases and global coherent soil spectral libraries (SSLs) that will allow to develop robust calibrations for multivariate prediction of soil properties applicable at the regional and the global scale. For example, SSLs have been developed recently, especially in the large-scale domain at different levels including national level (e.g., Brodsky et al., 2011; Knadel et al. 2012; Tsakiridis et al. 2017), European or continental level (Toth et al. 2013; Stevens et al. 2013; Romero et al. 2018) and global level (Viscarra Rossel et al. 2016). Then, associated with the upcoming availability of the next generation of hyperspectral Vis-NIR-SWIR satellite data for the entire globe, and the upcoming availability of improved tools for the extraction of soil properties, it shall pave the way for inexpensive methods for the delivery of high spatial-resolution, fully quantitative, soil properties maps to soil users.

\section{Conclusion: Observational Requirements and Future Directions in Imaging Spectroscopy}

\subsection{Summary of Achievements, Challenges and Prospect for the Use of Future Spaceborne Imaging Spectroscopy for Soil Applications}

Imaging spectroscopy of soils has proven the capability to enable the quantitative evaluation of many soil properties such as SOC, clay, iron, carbonates, sand and $\mathrm{pH}$, due to the presence of soil chromophores in the reflectance spectrum. Common properties modelling approaches use multivariate statistics based on soil data for calibration/validation or direct spectral features for the extraction of the soil properties. Then, good soil properties predictions can be achieved in local areas for exposed soils in appropriate surface conditions, as demonstrated in many papers from local-scale (airborne) to regional-scale (spaceborne) applications. With the upcoming availability of the next generation of orbiting hyperspectral sensors and routinely delivered high spectral resolution images for the entire globe, a new opportunity toward the operational quantitative monitoring of soil surfaces at large scales arises. These satellites would provide at the regional to the global scale (spatial resolution from 10 to $30 \mathrm{~m}$ ) routinely soil maps at different times. Besides the proven capabilities of IS air- and spaceborne technology for quantitative soil properties mapping, other specific fields in the soil science discipline can learn from this technology, such as soil mineralogy, soil chemistry, soil fertility, soil physics, soil microbiology, soil pollutions, fertilizers, management, weathering and conservation. 
Nonetheless, advances are still necessary to fully develop imaging spectroscopy soil products that can support, in a credible manner, global digital mapping and monitoring of soils as a support of societal needs for soil information. Challenges and gaps are identified due to low signal-to-noise ratio, geometric and optical distortions, atmospheric attenuation, vegetation cover, soil moisture and roughness effects, and sensing only of the first 100-200 $\mu \mathrm{m}$ (Ciani et al. 2005) of the soil body. Further identified challenges are the transfer of modelling approaches from the local to global scale and the availability of global soil data including harmonized soil spectral libraries, Attempts to overcome these problems are areas of intense research nowadays.

Precision agriculture and food security issues are two good examples where both point and imaging spectroscopy can be exploited. The development of the IS technology leans toward better quality sensors and miniaturization, but also on new development of platforms such as UAVs, balloons and micro-satellites. Together, this direction will enable more users to use the IS technology in general and for soil science in particular and will promise that this technology has a bright future for soil scientists, farmers and stakeholders.

\subsection{User and Observational Requirements}

Several recent studies looked at the potential of upcoming IS satellite missions for soil mapping, based on satellite-simulated data (Chabrillat et al. 2014; Castaldi et al. 2015, 2016; Gomez et al. 2015b; Steinberg et al. 2016). It was shown, e.g., that using simulated EnMAP data at $30 \mathrm{~m}$ resolution applying semi-operational methods, it is possible to predict soil properties such as SOC, clay and iron oxide content, with slightly reduced accuracy compared to airborne hyperspectral imagery at spatial scales $<5 \mathrm{~m}$. The spatial distribution of the soil properties was in general coherent between the simulated EnMAP and the airborne mapping, although the variability in spatial, spectral and radiometric resolutions. Castaldi et al. (2016) also clearly demonstrated the improvement in accuracy for the estimation of soil variables over bare soils using forthcoming hyperspectral imagers, as compared to current-generation multispectral sensors such as ALI, Landsat 8, Sentinel-2, covering spatial resolutions from 10 to $30 \mathrm{~m}$, but providing much lower spectral coverage and spectral resolution.

In this regard, we can define mission scenarios for two general user and observational requirements associated with two different spatial scales of user needs, linked to food security, resource management and sustainable agriculture (Table 2), such as (1) precision farming and (2) global mapping and monitoring of our soils status. These scenarios represent current technology trade-offs associated with IS technologies that could be used as mission requirements.

The first mission would provide the link between laboratory- and field-scale soil spectroscopy and will allow to support precision farming activities with the production of accurate soil properties maps at field scale for farmers and regional administrations to support, e.g., EU subsidy policies on fertilizer use, and improvement in SOC storage. This first user need is currently performed by laboratory analyses, field sensors and UAV and airborne sensors when possible. The given temporal requirement of 1 week would be useful to monitor short-term surface changes and is needed to catch the short bare-soil period between two cropping seasons. The second mission would focus on the production of large-scale soil maps for regional and national administration and impact at decision-making level of regional-scale, national and EU policies. 
Table 2 User and observational requirements for an imaging spectroscopy mission focused on soil properties mapping and food security

\begin{tabular}{lllll}
\hline User objective & Spatial requirements & $\begin{array}{l}\text { Temporal } \\
\text { requirements }\end{array}$ & $\begin{array}{l}\text { Spectral require- } \\
\text { ments }\end{array}$ & $\begin{array}{l}\text { Imaging spectros- } \\
\text { copy capabilities }\end{array}$ \\
\hline $\begin{array}{c}\text { Precision farming } \\
\text { (field scale) }\end{array}$ & GSD $<5 \mathrm{~m}$ & $\sim 1$ week & $\begin{array}{l}\text { Vis-NIR-SWIR } \\
\text { High spectral reso- } \\
\text { lution }<10 \mathrm{~nm}\end{array}$ & $\begin{array}{c}\text { Target mission/ } \\
\text { regional mapping }\end{array}$ \\
$\begin{array}{c}\text { Large-scale soil } \\
\text { mapping and } \\
\text { monitoring }\end{array}$ & GSD 20-30 m & $\sim 2$ weeks & $\begin{array}{l}\text { Vis-NIR-SWIR } \\
\text { High spectral reso- } \\
\text { lution } \sim 10 \mathrm{~nm}\end{array}$ & $\begin{array}{c}\text { Global mapping } \\
\text { mission }\end{array}$ \\
\hline
\end{tabular}

Soils are relevant to a long list of national, European and international policies, including the EU Soil Thematic Strategy, Common Agricultural Policy, Food Safety and Food security (FAO), UN Convention to Combat Desertification, and SOC is the common denominator. Overall, there is a need for more soil mapping at local level (target mission) and regional level (mapping mission). It has been widely recognized that a global effort for a better link between producers and users of soil and land information is needed that takes into account the ongoing developments in new and emerging technologies (such as remote sensing, mobile soil testing and digital soil mapping), availability of digital data (Webbased, app-based applications), ability of mid-users to utilize new soil information in policy- and decision- making relevant information, needs of the different stakeholders (farmer, regional administrator, country ministry) and impact at decision-making level (local and regional scale, national and EU policies) (Chabrillat et al. 2015).

New soil information to support societal needs can be brought by soil spectroscopy first at the laboratory and field scale, as it can be used in a preliminary way to analyse soil samples quickly and cheaply, and it combines well with digital soil mapping, secondly at the remote sensing scale from air- and spaceborne sensors for global soil mapping and monitoring. For this, the IS technology is available currently from hand-held, airborne and few spectrally limited spaceborne instruments, and soon potentially with high-quality data from global satellite missions at high spatial resolution $(<30 \mathrm{~m})$, which will no doubt support regional-scale soil mapping and soil monitoring combined with digital soil mapping approaches and soil datasets over the world. Nevertheless, further efforts are needed from the imaging spectroscopy community toward more methodological developments to fulfil the entire potential of soil spectroscopy from airborne and orbital vehicles.

Acknowledgements This paper is an outcome of a Workshop on requirements, capabilities and directions in spaceborne imaging spectroscopy held at the International Space Science Institute (ISSI) in Bern, Switzerland, in November 2016. The support of ISSI is gratefully acknowledged. The EnMAP science preparation program and EnMAP coordination team are gratefully acknowledged without which the ISSI Workshop would not have taken place.

\section{Compliance with Ethical Standards}

Conflict of interest The authors declare that they have no conflict of interest.

\section{References}

Adeline K, Gomez C, Gorretta N, Roger JM (2017) Predictive ability of soil properties to spectral degradation from laboratory Vis-NIR spectroscopy data. Geoderma 288:143-153 
Agassi M, Shainberg I, Morin J (1981) Effect of electrolyte concentration and soil sodicity on infiltration rate and crust formation. Soil Sci Soc Am J 45(5):848-851

Agassi M, Morin J, Shainberg I (1985) Effect of raindrop impact energy and water salinity on infiltration rates of sodic soils. Soil Sci Soc Am J 49:186-190

Aldana-Jague E, Heckrath G, Macdonald A, Van Wesemael B, Van Oost K (2016) UAV-based soil carbon mapping using VIS-NIR (480-1000 nm) multi-spectral imaging: potential and limitations. Geoderma 275(1):55-66

Alonso M, Rodríguez-Caballero E, Chamizo S, Escribano P, Cantón Y (2014) Evaluación de los diferentes índices para cartografiar biocostras a partir de información espectral. Rev Esp Teledetec 42:63-82

Arrouays D, Lagacherie P, Hartemink AE (2017) Digital soil mapping across the globe. Geoderma Reg 9:1-4

Bablet A, Jacquemoud S, Viallefond F, Fabre S, Briottet X (2017) Modeling bare soil reflectance in the solar domain as a function of water content and surface roughness. In: Abstract 10th EARSeL SIG Imaging Spectroscopy Workshop, 19-21 April 2017, Zurich, Switzerland

Bablet A, Vu PVH, Jacquemoud S, Viallefont-Robinet F, Fabre S, Briottet X, Sadeghid M, Whiting ML, Baret F, Tian J (2018) MARMIT: a multilayer radiative transfer model of soil reflectance to estimate surface soil moisture content in the solar domain (400-2500 nm). Remote Sens Environ 217:1-17

Bach H, Mauser W (1994) Modelling and model verification of the spectral reflectance of soils under varying moisture conditions. In: Proceedings IGARSS 94. 'Surface and atmospheric remote sensing: technologies, data analysis and interpretation', Pasadena, California, 8-12 August 1994, IEEE international. IEEE, Piscataway, NJ, pp 2354-2356

Bartholomeus H, Epema G, Schaepman M (2007) Determining iron content in Mediterranean soils in partly vegetated regions, using spectral reflectance and imaging spectroscopy. Int J Appl Earth Obs Geoinf 9:194-203

Bartholomeus H, Kooistraa L, Stevens A, van Leeuwen M, van Wesemael B, Ben-Dor E, Tychon B (2011) Soil organic carbon mapping of partially vegetated agricultural fields with imaging spectroscopy. Int J Appl Earth Obs Geoinf 13:81-88

Baumgardner MF, Silva LF, Biehl LL, Stoner ER (1985) Reflectance properties of soils. Adv Agron 38:1-44

Ben-Dor E, Banin A (1995a) Near infrared analysis (NIRA) as a method to simultaneously evaluate spectral featureless constituents in soils. Soil Sci 159(4):259-270

Ben-Dor E, Banin A (1995b) Near infrared analysis (NIRA) as a rapid method to simultaneously evaluate several soil properties. Soil Sci Soc Am J 59:364-372

Ben-Dor E, Inbar Y, Chen Y (1997) The reflectance spectra of organic matter in the visible near-infrared and short wave infrared region (400-2500) during a controlled decomposition process. Remote Sens Environ 61:1-15

Ben-Dor E, Irons JR, Epema GF (1999) Remote sensing of the earth sciences: manual of remote sensing. Soil Reflectance 3:111

Ben-Dor E, Patkin K, Banin A, Karnieli A (2002) Mapping of several soil properties using DAIS-7915 hyperspectral scanner data: a case study over clayey soils in Israel. Int J Remote Sens 23:1043-1062

Ben-Dor E, Goldlshleger N, Benyamini Y, Agassi M, Blumberg DG (2003) The spectral reflectance properties of soil structural crusts in the 1.2 to $2.5 \mu \mathrm{m}$ spectral region. Soil Sci Soc Am J 67(1):289-299

Ben-Dor E, Goldshalager N, Braun O, Kindel B, Goetz AFH, Bonfil D, Agassi M, Margalit N, Binayminy Y, Karnieli A (2004) Monitoring of infiltration rate in semiarid soils using airborne hyperspectral technology. Int J Remote Sens 25:1-18

Ben-Dor E, Levin TN, Singer A, Karnieli A, Braun O, Kidron GJ (2006) Quantitative mapping of the soil rubification process on sand dunes using an airborne hyperspectral sensor. Geoderma 131:1-21

Ben-Dor E, Taylor GR, Hill J, Demattê JAM, Whiting ML, Chabrillat S, Sommer S (2008) Imaging spectrometry for soil applications. Adv Agron J 97:321-392

Ben-Dor E, Chabrillat S, Demattê JAM, Taylor GR, Hill J, Whiting ML, Sommer S (2009) Using imaging spectroscopy to study soil properties. Remote Sens Environ 113:S38-S55

Ben-Dor E, Kafri A, Varacalli G (2014) SHALOM: an Italian-Israeli hyperspectral orbital mission-update. In: International geoscience and remote sensing symposium, Quebec, Canada, 13-18 July 2014

Ben-Dor E, Granot A, Notesco G (2017) A simple apparatus to measure soil spectral information in the field under stable conditions. Geoderma 306:73-80

Ben-Dor E, Chabrillat S, Demattê JAM (2018) Characterization of soil properties using reflectance spectroscopy. In: Thenkabail PS, Lyon JG, Huete A (eds) Hyperspectral remote sensing of vegetation, 2nd edn. Four volume set-volume I: fundamentals, sensor systems, spectral libraries, and data mining for vegetation. CRC Press, Boca Raton, pp 187-247. ISBN 978-1-138-05854-5

Benyamini Y, Unger PW (1984) Crust development under simulated rainfall on four soils. In: Agronomy abstracts. ASA, Madison, WI, pp 243-244 
Bishop JL, Pieters CM, Edwards JO (1994) Infrared spectroscopic analyses on the nature of water in montmorillonite. Clays Clay Miner 42:702-716

Blasch G, Spengler D, Hohmann C, Neumann C, Itzerott I, Kaufmann H (2015) Multitemporal soil pattern analysis with multispectral remote sensing data at the field-scale. Comput Electron Agric 113:1-13

Bogrekci I, Lee WS (2006) Effects of soil moisture content on absorbance spectra of sandy soils in sensing phosphorus concentrations using UV-VIS-NIR spectroscopy. Trans ASABE 49:1175-1180. https:// doi.org/10.13031/2013.21717

Boiffin J (1986) Stages and time-depedency of soil crusting in situ. In: Callebaut F, Gabriels D, De Boodt M (eds) Assessment of soil surface sealing and crusting. Flanders Research Center for Soil Erosion and Soil Conservation, Ghent, pp 91-98

Bowers S, Hanks RJ (1965) Reflectance of radiant energy from soils. Soil Sci 100:130-138

Brennan B, Bandeen WR (1970) Anisotropic reflectance characteristics of natural Earth surfaces. Appl Opt 9:405-412

Briottet X et al (2017) European Hyperspectral Explorer: HYPEX-2 - a new space mission for vegetation biodiversity, bare continental surfaces, coastal zones and urban area ecosystems. In: Abstract 10th EARSeL SIG imaging spectroscopy workshop, 19-21 April 2017, Zurich, Switzerland

Brodsky L, Klement A, Penizek V, Kodesova R, Boruvka L (2011) Building soil spectral library of the Czech soils for quantitative digital soil mapping. Soil Water Res 6:165-172

Brook A, Ben-Dor E (2014) Practical example of the supervised vicarious calibration (SVC) method: VALCALHYP airborne hyper spectra campaigns under EUFAR. In: EaRSeL eProceedings, no 2, pp 38-48

Brook A, Ben-Dor E (2015) Supervised vicarious calibration (SVC) of multi-source hyperspectral remote-sensing data. Remote Sens 7:6196-6223

Bryant R, Thoma D, Moran S, Holifield C, Goodrich D, Keefer T, Paige G, Williams D, Skirvin S (2003) Evaluation of hyperspectral, infrared temperature and radar measurements for monitoring surface soil moisture. In: Proceedings of the first interagency conference on research in the watersheds, Benson (USA), pp 528-533

Carmon N, Ben-Dor E (2017) An advanced analytical approach for spectral-based modelling of soil properties. Int J Emerg Technol Adv Eng 7:90-97

Castaldi F, Palombo A, Pascucci S, Pignatti S, Santini F, Casa R (2015) Reducing the influence of soil moisture on the estimation of clay from hyperspectral data: a case study using simulated PRISMA data. Remote Sens 7:15561-15582. https://doi.org/10.3390/rs71115561

Castaldi F, Palombo A, Santini F, Pascucci S, Pignatti S, Casa R (2016) Evaluation of the potential of the current and forthcoming multispectral and hyperspectral imagers to estimate soil texture and organic carbon. Remote Sens Environ 179:54-65

Castaldi F, Chabrillat S, Jones A, Vreys K, Bomans B, van Wesemael B (2018a) Soil organic carbon estimation in croplands by hyperspectral remote APEX Data using the LUCAS topsoil database. Remote Sens 10:153. https://doi.org/10.3390/rs10020153

Castaldi F, Chabrillat S, Chartin C, Genot V, Jones AR, van Wesemael B (2018b) Using LUCAS topsoil database to estimate soil organic carbon content in croplands sampled in Belgium and Luxembourg. Eur J Soil Sci 69(4):592-603

Castaldi F, Chabrillat S, van Wesemael B (2019) Sampling strategies for soil property mapping using multispectral Sentinel-2 and hyperspectral EnMAP satellite data. Remote Sens (in press)

Chabrillat S (2006) Land degradation indicators: spectral indices. Ann Arid Zone Spec Issue Land Special Assess 45(3-4):331-354

Chabrillat S, Goetz AFH, Krosley L, Olsen HW (2002) Use of hyperspectral images in the identification and mapping of expansive clay soils and the role of spatial resolution. Remote Sens Environ 82:431-445

Chabrillat S, Eisele A, Guillaso S, Rogaß C, Ben-Dor E, Kaufmann H (2011) HYSOMA: an easy-touse software interface for soil mapping applications of hyperspectral imagery. In: Proceedings 7 th EARSeL SIG imaging spectroscopy workshop, Edinburgh, Scotland

Chabrillat S, Whiting ML, Guillaso S, Eisele A, Haubrock SN, Kaufmann H (2012) Quantitative mapping of surface soil moisture with hyperspectral imagery using the HYSOMA interface. In: Abstract 2012 IEEE international geoscience and remote sensing symposium, IGARSS 2012, Muenchen, Germany

Chabrillat S, Foerster S, Steinberg A, Segl K (2014) Prediction of common surface soil properties using airborne and simulated EnMAP hyperspectral images: impact of soil algorithm and sensor characteristic. In: Proceedings 2014 IEEE international geoscience and remote sensing symposium, IGARSS 2014, Québec city, QC, Canada, pp 2914-2917

Chabrillat S, Hanegraaf M, Sommer R, van den Bosch R, Montanarella L, van Wesemael B, Schwilch G, Harthoorn J, Skalsky R, Braslow J, Mills J, Verzandvoort S, Obersteiner M (2015) Soil and 
land information: how to support decision making? Rapporteurs report, Global Soil Week 2015, Germany, 20-23 April 2015

Chabrillat S, Guillaso S, Rabe A, Foerster S, Guanter L (2016) From HYSOMA to ENSOMAP-a new open source tool for quantitative soil properties mapping based on hyperspectral imagery from airborne to spaceborne applications. General Assembly European Geosciences Union, Vienna, Austria, 2016, geophysical research abstracts, vol 18, EGU2016-14697

Chamizo S, Stevens A, Cantón Y, Miralles I, Domingo F, Van Wesemael B (2012) Discriminating soil crust type, development stage and degree of disturbance in semiarid environments from their spectral characteristics. Eur J Soil Sci 63:42-53

Chang DH, Islam S (2000) Estimation of soil physical properties using remote sensing and artificial neural network. Remote Sens Environ 74(3):534-544

Chang CW, Laird DA, Mausbach MJ, Hurburgh CR (2001) Near-infrared reflectance spectroscopy-principal components regression analyses of soil properties. Soil Sci Soc Am J 65:480-490

Ciani A, Goss KU, Schwarzenbach RP (2005) Light penetration in soil and particulate minerals. Eur J Soil Sci 56(5):561-574

Cierniewski J (1987) A model for soil surface roughness influence on the spectral response of bare soils in the visible and near-infrared range. Remote Sens Environ 23:97-115

Cierniewski J (2012) Satellite observation of bare soils for their average diurnal albedo approximation. In: Ist international conference on sensor networks, 24-26 February, 2012, Rome, Italy, pp 1-6

Cierniewski J, Courault D (1993) Bidirectional reflectance of bare soil surface in the visible and nearinfrared range. Remote Sens Rev 7:321-339

Cierniewski J, Guliński M (2010) Furrow microrelief influence on the directional hyperspectral reflectance of soil at various illumination and observation conditions. IEEE Trans Geosci Remote Sens 48(11):4143-4148

Cierniewski J, Gdala T, Karnieli A (2004) A hemispherical-directional reflectance model as a tool for understanding image distinctions between cultivated and uncultivated bare surfaces. Remote Sens Environ 90:505-552

Cierniewski J, Karnieli A, Hermann I, Królewicz S, Kuśnierek K (2010) Soil surface illumination at micro-relief scale and soil BRDF data collected by a hyperspectral camera. Int J Remote Sens 31:2151-2157

Cierniewski J, Karnieli A, Kuśnierek K, Herrmann I (2013) Approximating the average daily surface albedo with respect to soil roughness and latitude. Int J Remote Sens 34(9-10):3416-3424

Cierniewski J, Kaźmierowski C, Królewicz S (2015) Evaluation of the effects of surface roughness on the relationship between soil BRF data and broadband albedo. IEEE J Sel Top Appl Earth Obs Remote Sens 8(4):1528-1533

Cipra JE, Baumgardner MF, Stoner ER, MacDonald RB (1971) Measuring radiance characteristics of soil with a field spectroradiometer. Soil Sci Soc Am J 35:1014-1017

Corbane C, Raclot D, Jacob F, Albergel J, Andrieux P (2008) Remote sensing of soil surface characteristics from a multiscale classification approach. CATENA 75:308-318

Coulson KL, Reynolds DW (1971) The spectral reflectance of natural surfaces. J Appl Meteorol 10:1285-1295

Croft H, Anderson K, Kuhn NJ (2012) Reflectance anisotropy for measuring soil surface roughness of multiple soil types. CATENA 93:87-96

Croft H, Anderson K, Brazier ER, Kuhn NJ (2013) Modeling fine-scale soil surface structure using geostatistics. Water Resour Res 49:1858-1870

Croft H, Anderson K, Kuhn NJ (2014) Evaluating the influence of surface soil moisture and soil surface roughness on optical directional reflectance factors. Eur J Soil Sci 65:605-612. https://doi. org/10.1111/ejss.12142

Dalal RC, Henry RJ (1986) Simultaneous determination of moisture, organic carbon and total nitrogen by near infrared reflectance spectroscopy. Soil Sci Soc Am J 50:120-123

De Jong SM (1992) The analysis of spectroscopical data to map soil and types and soil crust of Mediterranean eroded soil. Soil Technol 5:199-211

Deering DW, Eck TF, Otterman J (1990) Bidirectional reflectance of selected desert surfaces and their three-parameter soil characterization. Agric For Meteorol 52:71-90

Dehaan R, Taylor GR (2003) Image-derived spectral endmembers as indicators of salinization. Int J Remote Sens 24:775-794

Demattê JA, Campos RC, Alves MC, Fiorio PR, Nanni MR (2004) Visible-NIR reflectance: a new approach on soil evaluation. Geoderma 121(1):95-112

Demattê JAM, Morgan CLS, Chabrillat S, Rizzo R, Franceschini MHD, FdaS Terra, Vasques GM, Wetterlind J (2015) Spectral sensing from ground to space in soil science: state of the art, applications, 
potential and perspectives. In: Thenkabail PS (ed) Remote sensing handbook-three volume set: land resources monitoring, modeling, and mapping with remote sensing. CRC Press, Boca Raton, pp 661-732. ISBN-10: 1482217953

Demattê JAM, Fongaro CT, Rizzo R, Safanelli JL (2018) Geospatial soil sensing system (GEOS3): a powerful data mining procedure to retrieve soil spectral reflectance from satellite images. Remote Sens Environ 212:161-175

Demetriades-Shah TH, Steven MD, Clark JA (1990) High resolution derivative spectra in remote sensing. Remote Sens Environ 33:55-64

Denis A, Stevens A, van Wesemael B, Udelhoven T, Tychon B (2014) Soil organic carbon assessment by field and airborne spectrometry in bare croplands: accounting for soil surface roughness. Geoderma 226-227:94-102. https://doi.org/10.1016/j.geoderma.2014.02.015

Diek S, Schaepman ME, de Jong R (2016) Creating multi-temporal composites of airborne imaging spectroscopy data in support of digital soil mapping. Remote Sens 8:906-934. https://doi.org/10.3390/ rs8110906

Diek S, Schaepmann M, de Jong R (2017a) Correcting airborne imaging spectroscopy data for soil moisture and soil surface roughness effects in support of digital soil mapping. In: Abstract 10th EARSeL SIG imaging spectroscopy workshop, 19-21 April 2017, Zurich, Switzerland

Diek S, Fornallaz F, Schaepman ME, de Jong R (2017b) Barest pixel composite for agricultural area using time series of Landsat data. Remote Sens 9(12):1245. https://doi.org/10.3390/rs9121245

Diek S, Chabrillat S, Nocita M, Schaepman ME, de Jong R (2019) Minimizing soil moisture variations in multi-temporal airborne imaging spectrometer data for digital soil mapping. Geoderma 337:607-621

Eisele A, Lau IC, Hewson R, Carter D, Wheaton B, Ong C, Cudahy TJ, Chabrillat S, Kaufmann H (2012) Applicability of the thermal infrared spectral region for the prediction of soil properties across semiarid agricultural landscapes. Remote Sens 4(11):3265-3286. https://doi.org/10.3390/rs4113265

Eisele A, Chabrillat S, Hecker C, Hewson R, Lau IC, Rogass C, Segl K, Cudahy TJ, Udelhoven T, Hostert P, Kaufmann H (2015) Advantages using the longwave infrared (LWIR) to detect and quantify semi-arid soil properties. Remote Sens Environ 163:296-311. https://doi.org/10.1016/j.rse.2015.04.001

Escribano P, Schmid T, Chabrillat S, Rodríguez-Caballero E, García M (2017) Optical remote sensing for soil mapping and monitoring. In: Pereira P, Brevik E, Muñoz-Rojas M, Miller B (eds) Soil mapping and process modelling for sustainable land use management. Elsevier, Amsterdam, pp 87-125. ISBN 978-0-12-805200-6

Eshel G, Levey G (2004) Spectral reflectance properties of crusted soils under solar illumination. Soil Sci Soc Am J 66:1982-1991

Eswaran H, Lal R, Reich PF (2001) Land degradation: an overview. In: Bridges EM, Penning de Vries FWT, Oldeman LR, Sombatpanit S, Scherr SJ (eds) Response to land degradation. Science Publishers, Inc., Enfield, NH, pp 20-35

European Commission (EC) (2006) Soil protection: the long story behind the strategy. Office for Official Publications of the European Communities, Luxembourg

Fabre S, Briottet X, Lesaignoux A (2015) Estimation of soil moisture content from the spectral reflectance of bare soils in the 0.4-2.5 $\mu \mathrm{m}$ domain. Sensors 15:3262-3281

FAO and ITPS (2015) Status of the world's soil resources (SWSR): main report. Food and Agriculture Organization of the United Nations, Rome

FAO/IIASA/ISRIC/ISS-CAS/JRC (2012) Harmonized World Soil Database (version 1.2). FAO, Rome

Folkman M, Pearlman J, Liao L, Jarecke P (2001) EO1/Hyperion hyperspectral imager design, development, characterization and prediction. In: Smith WL, Yasuoka Y (eds) Hyperspectral remote sensing of the land and atmosphere. SPIE proceeding, vol 4151, pp 40-51

Ge Y, Morgan CLS, Ackerson JP (2014) VisNIR spectra of dried ground soils predict properties of soils scanned moist and intact. Geoderma 221-222:61-69. https://doi.org/10.1016/j.geoderma.2014.01.011

Gerighausen H, Menz G, Kaufmann H (2012) Spatially explicit estimation of clay and organic carbon content in agricultural soils using multi-annual imaging spectroscopy data. Appl Environ Soil Sci. https:// doi.org/10.1155/2012/868090

Gholizadeh A, Borůvka L, Saberioon MM, Kozák J, Vašát R, Němeček K (2015) Comparing different data preprocessing methods for monitoring soil heavy metals based on soil spectral features. Soil Water Res 10(4):218-227

Gilley JE, Kottwitz ER (1995) Random roughness assessment by the pin and chain method. Appl Eng Agric 12(1):39-43

Gilliot JM, Vaudour E, Michelin J (2017) Soil surface roughness measurement: a new fully automatic photogrammetric approach applied to agricultural bare fields. Comput Electron Agric 134:63-78

Goetz AFH, Vane G, Solomon JE, Rock BN (1985) Imaging spectrometry for Earth remote sensing. Science 228:1147-1153 
Goldshleger N, Ben-Dor E, Benyamini Y, Blumberg D, Agassi M (2001) The spectral reflectance of soil's structural crust in the SWIR region 1.2-2.5 $\mu \mathrm{m}$. Terra-Nova 13(1):12-17

Goldshleger N, Ben-Dor E, Benyamini Y, Blumberg DG, Agassi M (2002) Soil crusting and infiltration process as monitored by soil reflectance spectroscopy in the SWIR Region. Int J Remote Sens 23(19):3909-3920

Goldshleger NE, Ben-Dor E, Benyamini Y, Agassi M (2004) Soil reflectance as a tool for assessing physical crust arrangement of four typical soils in Israel. Soil Sci 169:677-687

Goldshlager N, Ben-Dor E, Chudnovsky A, Agassi M (2010) Soil reflectance as a generic tool for assessing infiltration rate induced by structural crust for heterogeneous soils. Eur J Soil Sci 60:1038-1951

Gomez C, ViscarraRossel RA, McBratney AB (2008a) Soil organic carbon prediction by hyperspectral remote sensing and field VIS-NIR spectroscopy: an Australian case study. Geoderma 146:403-411

Gomez C, Lagacherie P, Coulouma G (2008b) Continuum removal versus PLSR method for clay and calcium carbonate content estimation from laboratory and airborne hyperspectral measurements. Geoderma 148:141-148

Gomez C, Lagacherie P, Coulouma G (2012a) Regional predictions of eight common soil properties and their spatial structures from hyperspectral Vis-NIR data. Geoderma 189-190:176-185

Gomez C, Lagacherie P, Bacha S (2012b) Using Vis-NIR hyperspectral data to map topsoil properties over bare soils in the Cap Bon region, Tunisia. In: Digital soil assessments and beyond-proceedings of the fifth global workshop on digital soil mapping, pp 387-392

Gomez C, Drost APA, Roger JM (2015a) Analysis of the uncertainties affecting predictions of clay contents from VNIR/SWIR hyperspectral data. Remote Sens Environ 156:58-70

Gomez C, Oltra Carrio R, Lagacherie P, Bacha S, Briottet X (2015b) Sensitivity of soil property prediction obtained from hyperspectral Vis-NIR imagery to atmospheric effects and degradation in image spatial resolutions. Remote Sens Environ 164:1-15

Gomez C, Gholizadeh A, Borůvka L, Lagacherie P (2016) Using legacy data for predicting soil surface clay content from VNIR/SWIR hyperspectral airborne images. Geoderma 276:84-92

Green R (2018) Global VSWIR imaging spectroscopy and the 2017 Decadal Survey. In: Proceedings of IGARSS 2018, IEEE international geoscience and remote sensing symposium, Valencia, Spain, 22-27 July 2018

Grunwald S, Thompson JA, Boettinger JL (2011) Digital soil mapping and modeling at continental scales: finding solutions for global issues. Soil Sci Soc Am J 75:1201

Guanter L, Kaufmann H, Segl K, Förster S, Rogass C, Chabrillat S, Küster T, Hollstein A et al (2015) The EnMAP spaceborne imaging spectroscopy mission for Earth observation. Remote Sens 7(7):8830-8857

Hapke BW (1981) Bidirectional reflectance spectroscopy I. Theory. J Geophys Res 86:3039-3054

Hartemink AE (2008) Soils are back on the global agenda. Soil Use Manag 24(4):327-330

Hartemink AE, McBratney AB (2008) A soil science renaissance. Geoderma 148:123-129

Haubrock S-N, Chabrillat S, Lemmnitz C, Kaufmann H (2008a) Surface soil moisture quantification models from reflectance data under field conditions. Int J Remote Sens 29(1):3-29

Haubrock S-N, Chabrillat S, Kuhnert M, Hostert P, Kaufmann H (2008b) Surface soil moisture quantification and validation based on hyperspectral data and field measurements. J Appl Remote Sens 2:023552

Heng BCP, Chandler JH, Armstrong A (2010) Applying close range digital photogrammetry in soil erosion studies. Photogramm Rec 25(131):240-265

Hill J, Schütt B (2000) Mapping complex patterns of erosion and stability in dry Mediterranean ecosystems. Remote Sens Environ 74:557-569

Hill J, Udelhoven T, Schütt B, Yair A (1999) Differentiating biological soil crusts in a sandy arid eco-system based on multi- and hyperspectral remote sensing data. In: Schaepmann M, Schläpfer D, Itten K (Eds) 1st EARSEL workshop on imaging spectroscopy. Proceedings of the EARSEL workshop, Zürich, 6-8 October 1998. EARSEL Secretariat, Paris, pp 427-436

Hook SJ, Hulley G, Cawse-Nicholson K (2017) HyTES, ECOSTRESS and HyspIRI-imaging spectroscopy and broad band imaging in the thermal infrared. In: Abstract 10th EARSeL SIG imaging spectroscopy workshop, 19-21 April 2017, Zurich, Switzerland

Hummel JW, Sudduth KA, Hollinger SE (2001) Soil moisture and organic matter prediction of surface and subsurface soils using an NIR soil sensor. Comput Electron Agric 32:149-165

Idso SB, Jackson RD, Reginato RJ, Kimball BA, Nakayama FS (1975) The dependence of bare soil albedo on soil water content. J Appl Meteorol 14:109-113

Jackson RD, Moran S, Slater PN, Biggar SF (1987) Field calibration of reflectance panels. Remote Sens Environ 22:145-158 
Janik LJ, Merry RH, Skjemstad JO (1998) Can mid infrared diffuse reflectance analysis replace soil extractions? Anim Prod Sci 38(7):681-696

Ji W, Viscarra Rossel RA, Shi Z (2015) Accounting for the effects of water and the environment on proximally sensed vis-NIR soil spectra and their calibrations. Eur J Soil Sci 66:555-565. https://doi. org/10.1111/ejss.12239

JRC, Jones A, Panagos P et al (2012) The state of soil in Europe: a contribution of the JRC to the European environments agency's environment state and outlook report-SOER 2010, JRC68418

Karnieli A, Kidron G, Ghassler C, Ben-Dor E (1999) Spectral characteristics of cyanobacteria soil crust in the visible near infrared and short wave infrared $(400-2,500 \mathrm{~nm})$ in semiarid environment. Int J Remote Sens 69:67-77

Knadel M, Deng F, Thomsen A, Greve HM (2012) Development of a Danish national Vis-NIR soil spectral library for soil organic carbon determination. In: Digital soil assessments and beyond: proceedings of the 5th global workshop on digital soil mapping 2012, Sydney, Australia, vol 43. CRC Press, Boca Raton

Kopačková V, Ben-Dor E, Carmon N, Notesco G (2017) Modelling diverse soil attributes with visible to longwave infrared spectroscopy using PLSR employed by an automatic modelling engine. Remote Sens 9(2):134

Kriebel KT (1976) On the variability of the reflected radiation field due to differing distributions of the irradiation. Remote Sens Environ 4:257-264

Kuester T, Spengler D, Barczi J-F, Segl K, Hostert P, Kaufmann H (2014) Simulation of multitemporal and hyperspectral vegetation canopy bidirectional reflectance using detailed virtual 3-D canopy models. IEEE Trans Geosci Remote Sens 52(4):2096-2108

Kuester T, Foerster S, Chabrillat S, Spengler D, Guanter L (2017) Assessing the influence of variable fractional vegetation cover on soil spectral features using simulated canopy reflectance modelling. In: Abstract 10th EARSeL SIG Imaging spectroscopy workshop, 19-21 April 2017, Zurich, Switzerland

Lagacherie P, Baret F, Feret JB, Netto JM, Robbez-Masson JM (2008) Estimation of soil clay and calcium carbonate using laboratory, field and airborne hyperspectral measurements. Remote Sens Environ 112:825-835

Lal R (2015) Restoring soil quality to mitigate soil degradation. Sustainability 7(5):5875-5895

Lee CM, Cable ML, Hook SJ, Green RO, Ustin SL, Mandl DJ, Middleton EM (2015) An introduction to the NASA Hyperspectral InfraRed Imager (HyspIRI) mission and preparatory activities. Remote Sens Environ 167:6-19

Lefèvre-Fonollosa MJ, Bajouk T, Briottet X, Carrère V, Delacourt, C, Feret JB, Gastellu-Etchegorry JP, Gomez C, Jacquemoud S, Le Dantec N, Marion R, Petit T, Weber C (2016) Preparing the future: the HYPXIM mission. In: 36th EARSeL symposium 2016, Bonn, Germany, 20-24 June 2016

Lekner J, Dorf MC (1988) Why some things are darker when wet. Appl Opt 27:1278-1280

Li Y, Liu Y, Wu S, Wang C, Xu A, Pan X (2017) Hyperspectral estimation of wheat biomass after alleviating of soil effects on spectra by non-negative matrix factorization. Eur J Agron 84:58-66

Liang S, Townshend JR (1996) A modified Hapke model for soil bidirectional reflectance. Remote Sens Environ 55(1):1-10

Liu W, Baret F, Gu XF, Zhang B, Tong Q, Zheng L (2003) Evaluation of methods for soil surface moisture estimation from reflectance data. Int J Rem Sens 24(10):2069-2083

Liu Y, Pan X, Wang C, Li Y, Shi R (2015) Predicting soil salinity with VisNIR spectra after removing the effects of soil moisture using external parameter orthogonalization. PLoS One. https://doi. org/10.1371/journal.pone.0140688

Lobell DB, Asner GP (2002) Moisture effects on soil reflectance. Soil Sci Soc Am J 66:722-727

Loizzo R, Guarini R, Longo F, Scopa T, Formaro R, Facchinetti C, Varavalli G (2018), PRISMA: the Italian hyperspectral mission. In: Proceedings of IGARSS 2018, IEEE international geoscience and remote sensing symposium, Valencia, Spain, 22-27 July 2018

Lu P, Wang L, Niu Z, Li L, Zhang W (2013) Prediction of soil properties using laboratory VIS-NIR spectroscopy and Hyperion imagery. J Geochem Explor 132:26-33

Malley DF, Martin P, Ben-Dor E (2004) Application in analysis of soils. Chapter 26. In: Craig R, Windham R, Workman J (eds) Near infrared spectroscopy in agriculture, vol 44. A three Societies Monograph. ASA, SSSA, CSSA, Madison, pp 729-784

Marzahn P, Rieke-Zapp D, Ludwig L (2012) Assessment of soil surface roughness statistics for microwave remote sensing applications using a simple photogrammetric acquisition system. ISPRS J Photogramm Remote Sens 72:80-89

Matsunaga T, Iwasaki A, Tsuchida S, Iwao K, Tanii, J, Kashimura O, Nakamura R, Yamamoto H, Kato S, Obata K, Mouri K, Tachikawa, T (2018) HISUI status toward FY2019 launch. In: Proceedings 
of IGARSS 2018, IEEE international geoscience and remote sensing symposium, Valencia, Spain, 22-27 July 2018

Matthias AD, Fimbres A, Sano EE, Post DF, Accily L, Batchily AK, Ferreira LG (2000) Surface roughness effects on soil albedo. SSSA J 63(3):1035-1041

McIntyre DS (1958) Permeability measurements of soil crusts formed by raindrop impact. Soil Sci 85(4):185-189

Meine C, Knight RL (eds) (1999) The essential Aldo Leopold: quotations and commentaries. University of Wisconsin Press, Madison

Milton EJ, Webb JP (1987) Ground radiometry and airborne multispectral survey of bare soils. Int J Remote Sens 18:3-14

Minasny B, McBratney AB (2006) A conditioned Latin hypercube method for sampling in the presence of ancillary information. Comput Geosci 32(9):1378-1388

Minasny B, McBratney AB, Bellon-Maurel V, Roger J-M, Gobrecht A, Ferrand L, Joalland S, Minasny B, Bellon-Maurel V, Gobrecht A, Roger J-M, Ferrand L, Joalland S (2011) Removing the effect of soil moisture from NIR diffuse reflectance spectra for the prediction of soil organic carbon. Geoderma 167-168:118-124. https://doi.org/10.1016/j.geoderma.2011.09.008

Moreno RG, Requejo AS, Alonso AMT, Barrington S, Alvarez MCD (2008) Shadow analysis: a method for measuring soil surface roughness. Geoderma 146:201-208

Muller E, Decamps H (2000) Modeling soil moisture-reflectance. Remote Sens Environ 76:173-180

Nanni MR, Demattê JAM (2006) Spectral reflectance methodology in comparison to traditional soil analysis. Soil Sci Soc Am J 70:393-407

Nocita M, Stevens A, Toth G, Panagos P, van Wesemael B, Montanarella L (2014) Prediction of soil organic carbon content by diffuse reflectance spectroscopy using a local partial least square regression approach. Soil Biol Biochem 68:337-347

Oldeman L, Hakkeling R, Sombroek W (1990) World map of the status of soil degradation, an explanatory note. International Soil Reference and Information Center, Wageningen

Ouerghemmi W, Gomez C, Naceur S, Lagacherie P (2011) Applying blind source separation on hyperspectral data for clay content estimation over partially vegetated surfaces. Geoderma 163(3-4):227-237

Ouerghemmi W, Gomez C, Nacer S, Lagacherie P (2016) Semi-blind source separation for estimation of clay content over semi-vegetated areas, from VNIR/SWIR hyperspectral airborne data. Remote Sens Environ 181:251-263

Palmer JM (1982) Field standards of reflectance. Photogramm Eng Remote Sens 48:1623-1625

Palmer KF, Williams D (1974) Optical properties of water in the near infrared. J Opt Soc Am 64:1107-1110

Panagos P, Borrelli P, Poesen J, Ballabio C, Lugato E, Meusburger K, Montanarella L, Alewell C (2015) The new assessment of soil loss by water erosion in Europe. Environ Sci Policy 54:438-447

Piech KR, Walker JE (1974) Interpretation of soils. Photogramm Eng 40:87-94

Potter KN, Horton R, Cruse RM (1987) Soil surface roughness effects on radiation reflectance and soil heat flux. Soil Sci Soc Am J 51:855-860

Previtali F (2014) Pedoenvironments of the Mediterranean countries: resources and threats. In: Kapur S, Ersahin S (eds) Soil Security for ecosystem management, chap 4. Springer, New York, NY, pp 61-82

Rast M, Nieke J, Ananasso C, Bach H, Ben Dor E, Chabrillat S, Colombo R, Feret JB, Giardino C, Green RO, Guanter L, Marsh S, Ong C, Rum G, Schaepman M, Schlerf M, Skidmore AK, Strobl P, Gascon F, Adams J, Isola C, Del Bello U (2019) The copernicus hyperspectral imaging mission for the environment (CHIME). In: Abstract 2019 ESA living planet symposium, Milan, Italy, 13-17 May 2019

Rieke-Zapp DH, Nearing MA (2005) Digital close range photogrammetry for measurement of soil erosion. Photogramm Rec 20(109):69-87

Rodger A, Cudahy T (2009) Vegetation corrected continuum depths at $2.20 \mu \mathrm{m}$ : an approach for hyperspectral sensors. Remote Sens Environ 113:2243-2257

Rodríguez-Caballero E, Escribano P, Cantón Y (2014) Advanced image processing methods as a tool to map and quantify different types of biological soil crust. ISPRS J Photogramm Remote Sens 90:59-67

Rogge D, Bauer A, Zeidler J, Mueller A, Esch T, Heiden U (2017) Building an exposed soil composite processor (SCMaP) for mapping spatial and temporal characteristics of soils with Landsat imagery (1984-2014). Remote Sens Environ 205:1-17

Romero DJ, Ben-Dor E, Demattê JAM, Souza AB, Vicente LE, Tavares TR, Martello M, Strabeli TF, da Silva Barros PP, Fiorio PR, Gallo BC, Sato MV, Eitelweind MT (2018) Internal soil standard method for the Brazilian soil spectral library: performance and proximate analysis. Geoderma 312:95-103

Rosa JD, Cooper M, Darboux F, Medeiros JC (2012) Soil roughness evolution in different tillage systems under simulated rainfall using a semivariogram-based index. Soil Tillage Res 124:226-232 
Rossel RV, Walvoort DJJ, McBratney AB, Janik LJ, Skjemstad JO (2006) Visible, near infrared, mid infrared or combined diffuse reflectance spectroscopy for simultaneous assessment of various soil properties. Geoderma 131(1):59-75

Schmid T, Koch M, Gumuzzio J (2008) Application of hyperspectral imagery to map soil salinity. In: Metternicht G, Zinck A (eds) Remote sensing of soil salinization: impact and land management. CRC Press, Boca Raton, pp 113-139 Chapter 7

Schmid T, Rodríguez-Rastrero M, Escribano P, Palacios-Orueta A, Ben-Dor E, Plaza A, Milewski R, Huesca M, Bracken A, Cicuéndez V, Pelayo M, Chabrillat S (2016) Characterization of soil erosion indicators using hyperspectral data from a Mediterranean rainfed cultivated region. IEEE J Sel Top Appl Earth Obs Remote Sens 9(2):845-860

Schwanghart W, Jarmer T (2011) Linking spatial patterns of soil organic carbon to topography: a case study from south-eastern Spain. Geomorphology 126:252-263

Schwartz G, Eshel G, Ben-Dor E (2011) Reflectance spectroscopy as a tool for monitoring contaminated soils. In: Pascucci S (ed) Soil contamination. InTech, Manhattan, pp 67-90

Selige T, Böhner J, Schmidhalter U (2006) High resolution topsoil mapping using hyperspectral image and field data in multivariate regression modeling procedures. Geoderma 136:235-244

Sellers PJ et al (1995) Remote sensing of the land-surface for studies of global change: models-algorithmsexperiments. Remote Sens Environ 51:3-26

Shoshany M (1993) Roughness-reflectance relationships of bare desert terrain: an empirical study. Remote Sens Environ 45:15-27

Shoshany M, Goldshleger N, Chudnovsky A (2013) Monitoring of agricultural soil degradation by remotesensing methods: a review. Int J Remote Sens 34(17):6152-6181

Steinberg A, Chabrillat S, Stevens A, Segl K, Foerster S (2016) Prediction of common surface soil properties based on Vis-NIR airborne and simulated EnMAP imaging spectroscopy data: prediction accuracy and influence of spatial resolution. Remote Sens 8(7):613

Stenberg B, Viscarra Rossel RA, Mouazen AM, Wetterlind J (2015) Visible and near infrared spectroscopy in soil science. In: Sparks DL (ed) Advances in agronomy, vol 107. Academic Press, Burlington, pp 163-215. https://doi.org/10.1016/s0065-2113(10)07005-7

Stevens A, van Wesemael B, Bartholomeus H, Rosillon D, Tychon B, Ben-Dor E (2008) Laboratory, field and airborne spectroscopy for monitoring organic carbon content in agricultural soils. Geoderma 144:395-404

Stevens A, Udelhoven T, Denis A, Tychon B, Lioy R, Hoffmann L, van Wesemael B (2010) Measuring soil organic carbon in croplands at regional scale using airborne imaging spectroscopy. Geoderma 158:32-45

Stevens A, Miralles I, Van Wesemael B (2012) Soil organic carbon predictions by airborne imaging spectroscopy: comparing cross-validation and validation. Soil Sci Soc Am J 76:2174-2183

Stevens A, Nocita M, Tóth G, Montanarella L, Van Wesemael B (2013) Prediction of soil organic carbon at the European scale by visible and near infrared reflectance spectroscopy. PLoS ONE 8(6):1-13

Stevens F, Bogaert P, van Wesemael B (2015) Detecting and quantifying field-related spatial variation of soil organic carbon using mixed-effect models and airborne imagery. Geoderma 259-260:93-103

Stolte J, Tesfai M, Øygarden L, Kværnø S, Keizer J, Verheijen F, Panagos P, Ballabio C, Hessel R (2016) Soil threats in Europe; EUR 27607

Stoner ER, Baumgardner MF (1981) Characteristic variations in reflectance of surface soils. Soil Sci Soc Am J 45:1161-1165

Taconet OV, Ciarletti V (2007) Estimating soil roughness indices on a ridge-and-furrow surface using stereo photogrammetry. Soil Tillage Res 93:64-76

Thomsen LM, Baartman JEM, Barneveld RJ, Starkloff T, Stolte J (2015) Soil surface roughness: comparing old and new measuring methods and application in a soil erosion model. Soil 1:399-410

Toth G, Jones A, Montanarella L (2013) The LUCAS topsoil database and derived information on the regional variability of cropland topsoil properties in the European Union. Environ Monit Assess 185:7409-7425

Toy TJ, Foster GR, Renard KG (2002) Soil erosion: processes, prediction, measurement, and control. Wiley, New York

Tsakiridis NL, Tziolas N, Dimitrakos A, Galanis G, Ntonou E, Tsirika A, Terzopoulou E, Kalopesa E, Zalidis GC (2017) Predicting soil properties for sustainable agriculture using Vis-NIR spectroscopy: a case study in northern Greece. In: Proceedings of SPIE 10444, fifth international conference on remote sensing and geoinformation of the environment (RSCy2017). https://doi. org/10.1117/12.2277905

Ulaby FT, Moore RK, Fung AK (1982) Microwave remote sensing active and passive. Addison-Wesley, Reading 
UNEP (2012) One planet, how many people? A review of Earth's carrying capacity, A discussion paper for the year of RIO+20. UNEP Global Environmental Alert Service

Ussiri DAN, Lal R (2018) The role of soil management and restoration in advancing sustainable development goals. In: Lal R, Horn R, Kosaki T (eds) Soil and sutainable development goals, vol 5. Catena, Stuttgart, pp 61-81

Van der Linden S, Rabe A, Held M, Jakimow B, Leitão PJ, Okujeni A, Schwieder M, Suess S, Hostert P (2015) The EnMAP-Box-a toolbox and application programming interface for EnMAP data processing. Remote Sens 7:11249-11266

Vermang J, Norton LD, Baetens JM, Huang C, Cornelis WM, Gabriels D (2013) Quantification of soil surface roughness evolution under simulated rainfall. Trans Am Soc Agric Biol Eng 56(2):505-514

Viscarra Rossel R, Behrens T, Ben-Dor E, Brown D, Demattê J, Shepherd K, Shi Z, Stenberg B, Stevens A, Adamchuk V (2016) A global spectral library to characterize the world's soil. Earth Sci Rev 155:198-230

Vrieling A, De Jong SM, Sterk G, Rodrigues SC (2008) Timing of erosion and satellite data: a multiresolution approach to soil erosion risk mapping. Int J Appl Earth Obs Geoinf 10(3):267-281

Wang Z, Coburn CA, Ren X, Teillet PM (2012) Effect of soil surface roughness and scene components on soil surface bidirectional reflectance factor. Can J Soil Sci 92:297-313

Weber B, Hill J (2016) Remote sensing of biological soil crusts at different scales. In: Weber B et al (eds) Biological soil crusts: an organizing principle in drylands. Springer, Cham, pp 215-234

Weber B, Olehowski C, Knerr T, Hill J, Deutschewitz K, Wessels DCJ et al (2008) A new approach for mapping of biological soil crusts in semidesert areas with hyperspectral imagery. Remote Sens Environ 112:2187-2201

Weksler S, Notespo G, Ben-Dor E (2017) an automated procedure for reducing atmospheric features and emphasizing surface emissivity in hyperspectral longwave infrared (LWIR) images. Int J Remote Sens. https://doi.org/10.1080/01431161.2017.1325535

Whiting ML, Li L, Ustin SL (2004a) Predicting water content using Gaussian model on soil spectra. Remote Sens Environ 89:535-552

Whiting ML, Li L, Ustin SL (2004b) Correcting mineral abundance estimates for soil moisture. In: Green RO (ed) 13th annual JPL airborne Earth science workshop, Pasadena, California, March 30-April 3, 2004. JPL Publication 05-3-1

Whiting ML, Palacios-Orueta A, Li L, Ustin SL (2005) Light absorption model for water content to improve soil mineral estimates in hyperspectral imagery. In: Pecora 16, global priorities in land remote sensing, Sioux Falls, South Dakota, 23-27 October 2005. American Society of Photogrammetry and Remote Sensing

Wu CY, Jacobson AR, Laba M, Baveye PC (2009) Accounting for surface roughness effects in the nearinfrared reflectance sensing of soils. Geoderma 152:171-180. https://doi.org/10.1016/j.geode rma.2009.06.002

Zhao X, Xue J-F, Zhang X-Q, Kong F-L, Chen F, Lal R et al (2015) Stratification and storage of soil organic carbon and nitrogen as affected by tillage practices in the North China Plain. PLoS ONE 10(6):e0128873

Publisher's Note Springer Nature remains neutral with regard to jurisdictional claims in published maps and institutional affiliations.

\section{Affiliations}

\section{S. Chabrillat ${ }^{1}$ (D) $\cdot$ E. Ben-Dor ${ }^{2} \cdot$ J. Cierniewski $^{3}$ (D) $\cdot$ C. Gomez ${ }^{4} \cdot$ T. Schmid $^{5}$. B. van Wesemael ${ }^{6}$}

1 Section Remote Sensing, Helmholtz Center Potsdam GFZ German Research Center for Geosciences, Telegrafenberg, 14473 Potsdam, Germany

2 Department of Geography and Human Environment, Tel Aviv University, 69978 Tel Aviv, Israel

3 Department of Soil and Remote Sensing Soil Science, Adam Mickiewicz University, Poznan, Poland 
4 UMR LISAH (INRA-IRD-SupAgro), IRD, 34060 Montpellier, France

5 Department of Environment, Centro de Investigaciones Energéticas, Medioambientes y Tecnológicas (CIEMAT), 28040 Madrid, Spain

6 Georges Lemaître Centre for Earth and Climate Research, Earth and Life Institute, Université Catholique de Louvain, 1348 Louvain-la-Neuve, Belgium 